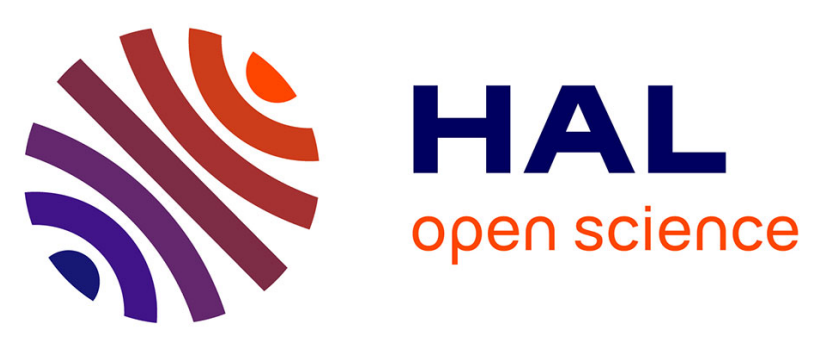

\title{
Density and Viscosity Measurements and Modeling of CO2-Loaded and Unloaded Aqueous Solutions of Potassium Lysinate
}

Riccardo Cremona, Serena Delgado, Alain Valtz, Antonio Conversano, Manuele Gatti, Christophe Coquelet

\section{To cite this version:}

Riccardo Cremona, Serena Delgado, Alain Valtz, Antonio Conversano, Manuele Gatti, et al.. Density and Viscosity Measurements and Modeling of CO2-Loaded and Unloaded Aqueous Solutions of Potassium Lysinate. Journal of Chemical and Engineering Data, inPress, 10.1021/acs.jced.1c00520 . hal-03457626

\section{HAL Id: hal-03457626 \\ https://hal.science/hal-03457626}

Submitted on 30 Nov 2021

HAL is a multi-disciplinary open access archive for the deposit and dissemination of scientific research documents, whether they are published or not. The documents may come from teaching and research institutions in France or abroad, or from public or private research centers.
L'archive ouverte pluridisciplinaire HAL, est destinée au dépôt et à la diffusion de documents scientifiques de niveau recherche, publiés ou non, émanant des établissements d'enseignement et de recherche français ou étrangers, des laboratoires publics ou privés. 


\title{
Density and Viscosity Measurements and Modelling of $\mathrm{CO}_{2}$-Loaded and Unloaded Aqueous Solutions of Potassium Lysinate
}

Riccardo Cremona ${ }^{1,2}$, Serena Delgado ${ }^{3}$, Alain Valtz ${ }^{3}$, Antonio Conversano ${ }^{1,2}$, Manuele Gatti ${ }^{1}$, Christophe Coquelet $^{3, *}$

1 Politecnico di Milano, Department of Energy, via Lambruschini 4, 20156 Milan, Italy

2 Laboratorio Energia e Ambiente Piacenza (LEAP), via Nino Bixio 27/C, 29121 Piacenza, Italy

3 Mines ParisTech, PSL University, CTP - Centre of Thermodynamics of Processes 35, rue Saint Honoré 77305

Fontainebleau Cedex France

*Corresponding author: christophe.coquelet@mines-paristech.fr

\begin{abstract}
This paper reports new experimental data and calibrated semi-empirical correlations concerning density and viscosity of aqueous solutions of Potassium Lysinate (LySK), a promising bio-based solvent for postcombustion $\mathrm{CO}_{2}$ capture from flue gases, an application of relevance for industrial decarbonization. The analysis covers a LysK molality range in the solution from $2.16 \mathrm{~m}$ to $4.44 \mathrm{~m}$, temperature intervals between $288.15 \mathrm{~K}$ and $358.15 \mathrm{~K}$, and a $\mathrm{CO}_{2}$ loading range of $0.3 \mathrm{molCO} / \mathrm{molLysK}-0.98 \mathrm{molCO}_{2} / \mathrm{molLysK}$. Newly collected experimental results supported the development and calibration of semiempirical correlations for density and viscosity of LysK solutions suitable to predict these thermophysical properties in the range of conditions tested. These models can predict the behaviour of the thermophysical properties investigated with high accuracy (for loaded solutions, average absolute deviation for density equal to $1.48 \mathrm{~kg} / \mathrm{m}^{3}$ and for viscosity of $0.04 \mathrm{mPas}$ ) within the whole range of LysK concentration, temperature and $\mathrm{CO}_{2}$ loading explored. Validation against literature data lying outside the calibration range shows an accuracy for density correlation $\leq 3 \%$, while for viscosity model deviations are larger and vary between $1 \%$ and $15 \%$ of the measured value.
\end{abstract}

Keywords: Potassium lysinate, $\mathrm{CO}_{2}$ capture, Chemical absorption, $\mathrm{CO}_{2}$-loading, Density, Viscosity 


\section{Introduction}

Post-combustion capture (PCC) is a mature technological solution which may employ chemical solvents to separate $\mathrm{CO}_{2}$ from flue gas streams. It is considered a benchmark $\mathrm{CO}_{2}$ capture technology for industrial and low-carbon power production applications ${ }^{1}$. Absorption by means of amine-based solvents has been already studied in the literature, with monoethanolamine (MEA) being widely employed at commercial scale ${ }^{2}$. MEA aqueous solutions are characterized by fast $\mathrm{CO}_{2}$ absorption rates and are available at a relatively low cost ${ }^{3,4}$. However, the chemical absorption process is still affected by a non-negligible energy duty required for solvent regeneration, environmental impacts associated with amine volatility, equipment cost, corrosion and degradation issues.

Given the considerable margin of improvement in PCC, and the necessity for a fast and widespread deployment of CCS technologies, the focus of research is moving towards potentially more efficient and environmentally-compatible solvents. In recent years, amino acid salts (AAS) solutions have drawn some attention as an alternative of interest to be further investigated in the perspective of possible applications in $\mathrm{CO}_{2}$ chemical absorption processes. Amino Acids are organic compounds characterized by the generic chemical structure $\mathrm{NH}_{2}-\mathrm{RCH}-\mathrm{COOH}$, which contains a carboxyl group (-COOH), an amino functional group ($\mathrm{NH}_{2}$ ), and a side chain ( $\mathrm{R}$ group) different for every amino acid. The amino acids salt solution is obtained by adding a strong base to an aqueous amino acid solution: the subsequent increase in $\mathrm{pH}$ allows the neutralization of the protonated amino group, increasing the aqueous solubility of the amino acid and enabling it to react with $\mathrm{CO}_{2}$, with a mechanism of reaction in line with the zwitterion mechanism proposed for conventional amines ${ }^{5}$.

Specifically, potassium lysinate (LysK) is indicated in literature as one of the most promising amino acid solutions ${ }^{6,8,9}$. At a concentration level of $43.7 \%$ mass fraction $(4.21 \mathrm{~m})$, LysK is expected to guarantee the same absorption capacity to that of $30 \% \mathrm{w} / \mathrm{w}$ MEA (benchmark solvent), and its fast kinetic when reacting with $\mathrm{CO}_{2}$ may reduce packing requirements ${ }^{10}$ of the related absorption unit. The maximum $\mathrm{CO}_{2}$ loading capacity and reaction kinetics of $\mathrm{CO}_{2}$ absorption in LysK solutions, assessed through vapour-liquid equilibrium ${ }^{8,11}$ and bench-scale absorption tests ${ }^{10}$, seem to outperform MEA.

Despite this, there are still many open items like corrosion, thermal degradation, toxicity of relative by products and regeneration energy, which can represent a limitation to the use of AAS in $\mathrm{CO}_{2}$ capture application via chemical absorption. Another topic of research is the formation of solid precipitate which may occur at high solvent concentration and high $\mathrm{CO}_{2}$ loading. This phenomenon can negatively affect the $\mathrm{CO}_{2}$ capture system by hindering the mass transfer and causing damages to the equipment. However, during the tests carried out in this and other works (Conversano et al. ${ }^{10}$ ), no solid precipitation has been reported. It is worth nothing that precipitation is a kinetically-controlled phenomenon, therefore the lack of observed precipitate can be a result of the duration of each experiment.

The design of a capture unit involves the definition of suitable rate-based modelling to evaluate mass and energy balance for the absorption column. Therefore, accurate correlations describing thermophysical properties like density and viscosity, are needed to carry out a suitable process design and a consistent performance evaluation of the process.

In effect, when acid gases (like $\mathrm{CO}_{2}$ ) are transferred from gas to liquid (liquid to gas) across an interface that separates them, the resistance to mass transfer in each phase causes a concentration gradient in each of them. The model of "double film" of Whiteman"12 is used to explain the behaviour of the absorption/desorption of acid gases in aqueous amine solutions. The mass transfer rate is proportional to liquid mass transfer coefficient, $K_{L}(\mathrm{~m} / \mathrm{s})$ and the gradient of concentration of solute from the interface and the liquid. 


$$
N_{A}=K_{L} *\left(C_{i}-C\right)
$$

When chemical reactions occur in the bulk liquid phase, a (dimensionless) enhancement factor, $E$ is introduced. Correlations are considered to estimate the mass transfer coefficient. The correlation is defined by $S h=A R e^{a} S c^{b}$. The Sherwood, Reynolds and Schmidt dimensionless numbers are calculated using Eqs. 2 to 4 , respectively.

$$
\begin{aligned}
& S h=\frac{K_{L} L}{D} \\
& R e=\frac{\rho v L}{\mu} \\
& S c=\frac{\mu}{\rho D}
\end{aligned}
$$

Where $\rho$ is the density, $\mu$ is the dynamic viscosity, $L$ the characteristic length (in our case the diameter of the magnetic stirrer), $D$ the coefficient of diffusion (for $\mathrm{CO}_{2}$ or $\mathrm{H}_{2} \mathrm{~S}$ ) and $v$ the speed.

In this context, according to Mota-Martinez ${ }^{13}$, the viscosity of the solvent employed in the $\mathrm{CO}_{2}$ absorption process is one of the most relevant drivers for solvent selection. In fact, viscosity is one of the key properties affecting the interphase heat and mass transfer involved in chemical absorption, with direct consequences on the size of process units and on the performance and cost of the capture plant. Mota-Martinez ${ }^{13}$ calculate an increase of $5 \%$ in total annualised cost of the $\mathrm{CO}_{2}$ capture process when increasing solvent viscosity by $20 \%$ compared with benchmark $51 \$ / \mathrm{t}_{\mathrm{CO} 2}$ with a $30 \mathrm{wt} \%$ MEA solution at $303 \mathrm{~K}$. This is due to a significant reduction in the mass transfer of the gas in the liquid phase for two reasons: slower diffusion of the solubilised gas through the gas-liquid interface, and less favourable hydrodynamics of the liquid film, especially the mass transfer coefficient ${ }^{14}$. As a matter of fact, the benchmark correlation by Onda et al. ${ }^{15}$ on liquid mass transfer $\left(\mathrm{k}_{\mathrm{L}}\right)$ in a randomly packed column gives a $14 \%$ decrease in mass transfer coefficient when viscosity $(\mu)$ increases by $\left.20 \%\left(k_{\mathrm{L}} \propto \mu^{-5 / 6}\right)\right)$. Besides, higher values of viscosity are associated with higher friction factors and pressure drops, thus an increase in auxiliaries power consumption is also expected ${ }^{13,14}$. In turn, high values of solvent densities are linked with a cost reduction related with the solvent circulation system (e.g. pumps and pipes) ${ }^{13}$.

Potassium lysinate is a relatively novel solvent, thus a limited number of studies and very few experimental data are available in the scientific literature. Thermophysical properties of LysK, such as densities, viscosities, specific heat capacity, thermal conductivity, surface tension, have been investigated by several research groups $^{16-20}$, but there is still a lack of data especially for highly concentrated solutions, loaded solutions and at high temperature levels, typical of the regeneration section. To the best of authors' knowledge, there is only one work that has determined the effect of dissolved carbon dioxide on density and viscosity of LysK solutions, so far ${ }^{16}$. Table 1 reports, in chronological order, the experimental works on aqueous LysK density and viscosity that have been published so far, specifying solvent concentration, investigated temperature range and the eventual $\mathrm{CO}_{2}$ loading of the solvent.

Table 1 Thermophysical properties of LysK solutions available in literature. The literature review included LysK molarity $(M)[\mathrm{mol} L \mathrm{LyK} / \mathrm{L}]$ and LysK molality $(\mathrm{m})\left[\mathrm{mol}_{\text {Lysk }} / \mathrm{kg}_{\text {water }}\right], \mathrm{CO}_{2}$ Loading $\left[\mathrm{molCO}_{2} / \mathrm{mol}_{\text {Lysk }}\right]$, temperature range $[\mathrm{K}]$.

\begin{tabular}{cllll}
\hline Property & LysK Concentration & $\begin{array}{l}\mathrm{CO}_{2} \text { loading } \\
{\left[\mathrm{molCO}_{2} / \text { molLysK }\right]}\end{array}$ & $\begin{array}{l}\text { Temperature } \\
\text { range }[\mathrm{K}]\end{array}$ & Reference \\
\hline Density & $0.2 \mathrm{M}-3 \mathrm{M}$ & $0.3-1.1^{*}$ & $298.15-348.15 \mathrm{~K}$ & Shen et al. ${ }^{16}$ \\
\hline
\end{tabular}




\begin{tabular}{cllll}
\hline Density & $0.5 \mathrm{M}, 1.5 \mathrm{M}, 2.5 \mathrm{M}$ & $/$ & $298-313 \mathrm{~K}$ & Mazinani et al. ${ }^{17}$ \\
\hline Density & $0.25 \mathrm{M}-2.5 \mathrm{M}$ & $/$ & $293.15-353.15 \mathrm{~K}$ & Bian et al. ${ }^{18}$ \\
\hline Density & $0.2 \mathrm{M}-0.5 \mathrm{M}{ }^{* *}$ & $/$ & $303-323 \mathrm{~K}$ & Ramezani et al. ${ }^{19}$ \\
\hline Density & $2.28 \mathrm{~m}, 3.51 \mathrm{~m}, 5.19 \mathrm{~m}^{* * *}$ & $/$ & $303.15-343.15 \mathrm{~K}$ & Suleman et al. ${ }^{20}$ \\
\hline Viscosity & $0.2 \mathrm{M}-3 \mathrm{M}$ & $0.3-1.1^{*}$ & $298.15-348.15 \mathrm{~K}$ & Shen et al. ${ }^{16}$ \\
\hline Viscosity & $0.5 \mathrm{M}, 1.5 \mathrm{M}, 2.5 \mathrm{M}$ & $/$ & $298-313 \mathrm{~K}$ & Mazinani et al. ${ }^{17}$ \\
\hline Viscosity & $0.25 \mathrm{M}-2.5 \mathrm{M}$ & $/$ & $293.15-353.15 \mathrm{~K}$ & Bian et al. ${ }^{18}$ \\
\hline Viscosity & $0.2 \mathrm{M}-0.5 \mathrm{M}{ }^{* *}$ & $/$ & $303-323 \mathrm{~K}$ & Ramezani et al. ${ }^{19}$ \\
\hline Viscosity & $2.28 \mathrm{~m}, 3.51 \mathrm{~m}, 5.19 \mathrm{~m}^{* * *}$ & $/$ & $303.15-343.15 \mathrm{~K}$ & Suleman et al. ${ }^{20}$
\end{tabular}

* The $\mathrm{CO}_{2}$ loading effect was evaluated only on the 2.5M LysK solution

** Blended with 2M MEA solution

***@303.15 correspond respectively to 1.72 M, 2.35 M, 3.01 M

Therefore, additional experimental data covering an extended LysK concentration range as well as carbonated solutions are required for developing rigorous process simulations, rate-based models and techno-economic assessments, in order to better evaluate the potential of the solvent and further explore its application in $\mathrm{CO}_{2}$ capture processes.

The objective of this work is to provide new experimental data regarding thermophysical properties of $\mathrm{CO}_{2}$ loaded LysK solutions such as viscosity and density, covering a $\mathrm{CO}_{2}$ loading range of around $0.3-1$

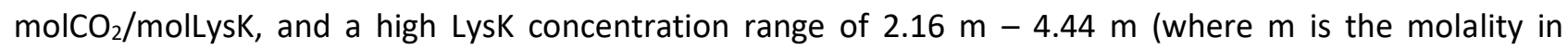
mol Lysk $/ \mathrm{kg}_{\text {H2O }}$ ) referred to as a range of interest in previous studies ${ }^{10}$. Moreover, this article also aims at proposing and calibrating new semi-empirical correlations for density and viscosity, based on the new data collected.

The work is organized as follows: section 0 outlines the experimental campaigns, starting with the summary on rationale and motivations of the tests performed, a description of the experimental facility employed and the procedure for preparing LysK solutions. Section 3 presents the numerical results obtained during the experiments. Section 4 is dedicated to modelling and numerical data processing, including an overview on the models used to correlate experimental density and viscosity and the regression analysis. In section 5 the results obtained are discussed in terms of physical behaviour and dependencies of the measured quantities; the accuracy of the models developed is analysed and a comparison with literature data and the benchmark solvent is provided. Section 6 contains the main conclusions, possible improvements, and future perspectives to advance the state of the art of amino acid salts for $\mathrm{CO}_{2}$ chemical absorption.

\section{Material and methods}

\subsection{Solution preparation}

The salts of amino acids are formed by adding an equimolar amount of a strong base to the amino acid under investigation. In this case, potassium hydroxide ( $\mathrm{KOH} 85 \%$ purity) is added to a solution of deionised water and L-lysine ( $98 \%$ purity) to form potassium lysinate solutions. Water was purified by a Millipore system with a $0.22 \mu \mathrm{m}$ membrane. A list of the chemicals used in this work is provided in Table 2. 
To reach the target potassium lysinate concentration in water, weight measurements have been performed using an electronic analytical balance (Mettler-Toledo XS205) with an accuracy of $0.1 \mathrm{mg}$.

The aspects that affect the uncertainty of LysK concentration in the aqueous solution include the accuracy of the instrument (type-B uncertainty), the standard error of the mean linked to the repeatability of the weight measurements (type-A uncertainty) and the uncertainty related to the purity if the chemicals used. A detailed analysis of the uncertainty determination is provided in the Supporting Information (SI) file.

The $\mathrm{CO}_{2}$-loaded solutions are obtained using a variable volume press under vacuum where the unloaded solution is introduced after being degassed. Afterwards, the desired amount of $\mathrm{CO}_{2}$ is injected in the press from a separate vessel of known volume with constantly monitored pressure and temperature conditions via a pressure transducer $\left(\mathrm{U}_{\mathrm{B}}(\mathrm{P})=3 \mathrm{mbar}\right)$ and a platinum probe $\left(\mathrm{U}_{\mathrm{B}}(T)=0.02 \mathrm{~K}\right)$. The initial and final densities of $\mathrm{CO}_{2}$ in the intermediate vessel are then determined using the equation of state provided by Span and Wagner ${ }^{21}$ within the REFPROP database ${ }^{22}$ (Version 10.0), given initial and final pressure and temperature conditions. The number of moles of carbon dioxide loaded into the press can be calculated by measuring the density variation inside the $\mathrm{CO}_{2}$ vessel:

$$
n_{\mathrm{CO}_{2}}=V_{\text {vessel }} *\left(\rho_{1}-\rho_{2}\right) * \frac{1}{M_{\mathrm{CO}_{2}}}
$$

The values of $\mathrm{CO}_{2}$ densities $\left(\rho_{1}, \rho_{2}\right)$, in $\mathrm{kg} / \mathrm{m}^{3}$ depend on vessel pressure and temperature, while $V_{\text {vessel }}$ and $\mathrm{M}_{\mathrm{CO}_{2}}$ indicate, respectively, the volume of the vessel $\left(\mathrm{m}^{3}\right)$ and the molecular weight of carbon dioxide $(\mathrm{kg} / \mathrm{mol})$. To completely dissolve $\mathrm{CO}_{2}$ in the amino acid solution and to guarantee monophasic liquid phase, the two components are compressed inside the press using an external gas bottle with pressurized nitrogen at a pressure greater than the bubble pressure of $\mathrm{CO}_{2}$ ( $0.5 \mathrm{Mpa}$ for several hours).

Uncertainty on the number of moles of $\mathrm{CO}_{2}$ can be derived by applying the formula of the combined uncertainty to Eq. 5, knowing the accuracy of the equation of state by Span and Wagner provided in their work $^{21}$. As described in the SI file, the combination of the uncertainty on LysK concentration and on the number of moles of $\mathrm{CO}_{2}$ dissolved gives the final uncertainty value on the $\mathrm{CO}_{2}$ loading of the solution.

Table 2: List of the chemicals used in this work along with the vendor, molecular weight (M), purity and molecular structure.

\begin{tabular}{|c|c|c|c|c|c|c|}
\hline Chemical & Abbreviation & $\begin{array}{c}\text { CAS } \\
\text { number }\end{array}$ & Source & $\begin{array}{c}M \\
{[\mathrm{~g} / \mathrm{mol}]}\end{array}$ & $\begin{array}{l}\text { Purity }^{\mathrm{a}} \\
{[\% \mathrm{w} / \mathrm{w}]}\end{array}$ & Chemical structure \\
\hline L-Lysine & L-Lys & $56-87-1$ & Acros & 146.19 & 98 & $\mathrm{NH}_{2}-\left(\mathrm{CH}_{2}\right)_{4}-\underset{\mathrm{I}}{\mathrm{C}}-\mathrm{C}-\mathrm{COOH}$ \\
\hline $\begin{array}{l}\text { Potassium } \\
\text { Hydroxide }\end{array}$ & $\mathrm{KOH}$ & $1310-58-3$ & $\begin{array}{l}\text { Fischer } \\
\text { Chemicals }\end{array}$ & 56.11 & 85 & $\mathrm{~K}^{-\mathrm{O}}{ }_{\mathrm{H}}$ \\
\hline $\begin{array}{l}\text { Carbon } \\
\text { Dioxide }\end{array}$ & $\mathrm{CO}_{2}$ & $124-38-9$ & Messer & 44.01 & 99.995 & $\mathrm{O}=\mathrm{C}=\mathrm{O}$ \\
\hline
\end{tabular}

${ }^{a}$ Gas Chromatography

\subsection{Summary of the experimental campaigns}

The LysK concentration level in the aqueous solutions investigated in this work ranges from $2.16 \mathrm{~m}$ to 4.44 $\mathrm{m}$. In total, five different LysK molality concentrations in aqueous solutions have been tested during the experimental campaigns, and their values are listed in Table 3 together with the corresponding uncertainties. 
The procedure used to estimate the uncertainty on LysK concentration is explained in paragraph 1 of the Supporting Information (SI) file.

Table 3: Concentration level (molality mol $_{L y s K} / \mathrm{kg}_{\text {water }}$ ) of the LysK solutions tested in this work and the standard uncertainty value u(w).

\begin{tabular}{l|c|c|c|c|c}
\hline $\begin{array}{l}\text { LysK concentration level } \\
\text { [mol }\end{array}$ LysK $/ \mathrm{kg}_{\text {water }}$ & 2.16 & 2.93 & 3.65 & 4.21 & 4.44 \\
\hline $\begin{array}{l}\text { Standard uncertainty on LysK concentration } \\
\text { in solution } \mathrm{u}(\mathbf{w}) \text { [mol } \mathrm{m}_{\text {Lsk }} / \mathrm{kg}_{\text {water }} \text { ] }\end{array}$ & 0.10 & 0.10 & 0.13 & 0.13 & 0.11 \\
\hline
\end{tabular}

An overview of the experimental campaigns carried out is reported in Table 4. For all the five different LysK concentrations, thermophysical properties of the unloaded solution have been studied. For what concerns $\mathrm{CO}_{2}$-loaded solutions, the experiments focused on a LysK mass fraction of $43.7 \%(4.21 \mathrm{~m})$, indicated in literature as a promising concentration level to obtain the same absorption capacity as the benchmark solvent $30 \% \mathrm{MEA}^{10}$. The explored temperature and loading ranges reflect the conditions envisaged during the capture processes (avoiding the region in which solid precipitation may occur), in the absorber ${ }^{2}$. Therefore, $\mathrm{CO}_{2}$ loading varies between 0.3 and around $0.9 \mathrm{molCO} / \mathrm{molLysK}$.

Table 4: Summary of the experimental campaigns carried out on thermophysical properties of LysK solutions (concentration level expressed in molality $m$ )

\begin{tabular}{|c|c|c|c|c|}
\hline & \multicolumn{2}{|c|}{$\begin{array}{l}\text { LysK molality values investigated [m]: } \\
2.16-2.93-3.65-4.21-4.44\end{array}$} & \multicolumn{2}{|c|}{$\begin{array}{l}\text { LysK molality value investigated: } \\
\qquad 4.21 \mathrm{~m}\end{array}$} \\
\hline & $\begin{array}{l}\text { Density } \\
\text { Measurements }\end{array}$ & $\begin{array}{l}\text { Viscosity } \\
\text { Measurements }\end{array}$ & $\begin{array}{l}\text { Density } \\
\text { Measurements }\end{array}$ & $\begin{array}{c}\text { Viscosity } \\
\text { Measurements }\end{array}$ \\
\hline $\begin{array}{l}\mathrm{CO}_{2} \text { Loading range } \\
{\left[\mathrm{molCO}_{2} / \mathrm{molLysK}\right]}\end{array}$ & 0 & 0 & $0.29-0.98$ & $0.33-0.81$ \\
\hline Temperature range [K] & $288.15-343.15$ & $293.15-343.15$ & $293.15-358.15$ & $293.15-343.15$ \\
\hline
\end{tabular}

\subsection{Density measurements}

The Anton Paar DSA 5000 M density meter is used to determine densities of LysK solutions. The working principle of the densimeter is based on the oscillating $\mathrm{U}$-shaped tube method ${ }^{23}$. Once the sampled liquid is introduced in the measurement cell, the U-tube is vibrated at its characteristic frequency, while optical pickups observe its changes which depend on the density of the solution. The latter is determined via the following mathematical model ${ }^{24}$ :

$$
\rho=K_{A} * Q^{2} * f_{1}-K_{B} * f_{2}
$$

Where $\rho$ is the density in $\mathrm{gcm}^{-3}, K_{A}$ and $K_{B}$ are specific constants of the instrument, $Q$ is the quotient of the period of oscillation of the $U$-tube divided by the period of oscillation of the reference oscillator, $f_{1}$ and $f_{2}$ are correction terms for temperature, viscosity and non-linearity.

Temperature is controlled by two Pt 100 thermometers and Peltier elements, with an accuracy guaranteed by the manufacturer of $0.01 \mathrm{~K}$ and a maximum temperature level of $343.15 \mathrm{~K}$.

For $\mathrm{CO}_{2}$-loaded solutions, Nitrogen at $0.5 \mathrm{MPa}$ is used as pressurising agent to move the piston of the variable-volume press and make the loaded solution flow inside the measurement cell of the densimeter. A scheme describing the connection between the cell containing the $\mathrm{CO}_{2}$ loaded solvent and the measurement cell of the densimeter is graphically represented in Figure 1.

A new version of the Anton Paar DSA $5000 \mathrm{M}$, able to measure up to $363.15 \mathrm{~K}$, but featuring the same accuracy, operating principle and configuration as the previous one, is employed for this purpose. 
The density measurements of unloaded LysK solutions were performed in three different cycles to check their repeatability.

As a result, the uncertainty $u$ is determined with Eq. 7:

$$
u=\sqrt{\left(\frac{u_{R B}}{\sqrt{3}}\right)^{2}+\left(\frac{s}{\sqrt{N}}\right)^{2}}
$$

Where $u_{R B}$ is the accuracy of the densimeter (type-B uncertainty), $s$ is the standard error of the mean (typeA uncertainty) of the three different measurement cycles $(N)$.

\subsection{Viscosity measurements for unloaded LysK solutions}

The viscosity measurements have been carried out using an Anton Paar LOVIS 2000 ME viscometer. It is a modular instrument to be coupled with a densimeter; in this case it is coupled with the Anton Paar DSA 5000 $M$ density and sound velocity meter. The solution sample under testing is filled into a glass capillary (diameter of $1.59 \mathrm{~mm}$ ) which is introduced into a temperature controlled capillary block. This block can be inclined at a variable predefined angle according to the calibration performed. The capillary had already been calibrated with appropriate standard fluids ${ }^{25}$.

The LOVIS 2000 ME viscometer is based on the falling ball method: by measuring the falling time of a steel ball in the capillary tube filled with the sample fluid and inclined at different angles, it automatically provides the viscosity value for the specified temperature level. The equation governing this principle (i.e. the calibration curve of the instrument) is the following ${ }^{25}$ :

$$
\mu=K_{1} *\left(\rho_{K}-\rho_{S}\right) * t_{1}
$$

where $\mu$ is the dynamic viscosity of the sample solution in mPas; $K_{1}$ is the calibration constant of the measuring system; $\rho_{K}$ is the ball (steel) density in $\mathrm{gcm}^{-3} ; \rho_{S}$ is the sample density in $\mathrm{gcm}^{-3}$, measured by the instrument, and $t_{1}$ is the rolling time in seconds ${ }^{25}$. The DSA $5000 \mathrm{M}$ density meter and LOVIS $2000 \mathrm{ME}$ viscometer are not equipped with pressure transducer. In consequence, the value of atmospheric pressure is given by GE Druck DPI 142, Precision Barometic Indicator with an accuracy of $u(P)=0.035 \mathrm{kPa}$.

The same procedure used to evaluate the experimental uncertainty on the density values, is also employed for the viscosity measurements of LysK unloaded solution. The full calculations are reported in the SI file paragraph 4.

\subsection{Viscosity measurements for $\mathrm{CO}_{2}$ loaded LysK solutions}

The instrument used for the viscosity measurement of potassium lysinate loaded solutions is the Flucon QVis $01 / L^{26}$. It is a vibrating quartz viscometer that transduces the viscosity of the surrounding fluid into the resonance frequency of an oscillating quartz sensor. The torsional oscillation is caused by the creation of an electrical field: the oscillation of the sensor produces a high frequency shearing (approx. $56 \mathrm{kHz}$ ) of the measuring sample. The dampening of the system is mainly influenced by the viscosity of the liquid sample.

A scheme of the experimental test bench is reported in Figure 2. The quartz sensor is inserted in a cell, of around $20 \mathrm{~mL}$ volume, immersed in an isothermal water bath with temperature control $\pm 0.1 \mathrm{~K}$. A platinum probe and a pressure transducer allow for the measurement of pressure and temperature conditions of the fluid inside the cell. The $\mathrm{CO}_{2}$-loaded solution is introduced in the measurement cell by means of a press, pushed by nitrogen at $0.5 \mathrm{MPa}$. The circuit is completed with a vacuum pump which provides the necessary vacuum conditions inside the cell before starting the measurements.

The Flucon QVis viscometer consists in a torsional quartz vibrator (TQV) that, when is immersed in a viscous medium, is able to measure the visco-elastic properties from the resonance frequency of the oscillating 
sensor. According to Laesecke et al. ${ }^{27}$, a purely torsional stress will produce purely shearing deformation in the fluid without any other displacement normally to the surface, thus, only the viscous-elastic effects have an influence on the oscillating frequency.

The working principle of a TQV is based on the equation derived by Webeler ${ }^{27}$, and it gives the product between the dynamic viscosity and the density of the liquid sample:

$$
\mu[P a s] * \rho\left[k g m^{-3}\right]=\left(\frac{m}{S}\right)^{2} *(\pi f) *\left(\frac{\Delta f}{f}-\frac{\Delta f_{0}}{f_{0}}\right)^{2}
$$

Where $m$ is the mass of the quartz crystal $(\mathrm{kg}), S$ is the surface area exposed to the viscous medium $\left(\mathrm{m}^{2}\right), f$ is the resonance frequency under test conditions $(\mathrm{Hz}), \Delta f$ is the associated bandwidth of the resonance curve under test conditions $(\mathrm{Hz}), f_{0}$ and $\Delta f_{0}$ are, respectively, the resonance frequency and its associated bandwidth in vacuum conditions $(\mathrm{Hz})$.

Therefore, from the values of resonance frequency measured by the instrument it is possible to predict the viscosity of the solution sample under test conditions, by means of a suitable empirical correlation. This logarithmic relationship, reported in Eq. 10, is derived from the model of TQVs reported in Eq. 9, to which a term describing temperature influence is introduced, together with the density factor from Eq. 9, and with two terms expressing the relationship with frequency $f$. The frequency dependence is described by a linear and sixth power polynomial contribution, chosen for their statistical representativeness. Other factors, such as $\Delta f, m$ or $S$ could not be included in the model because they are not available from the instrument datasheet, nor they could be directly measured. This approach is required since the liquid viscosity not only depends on the resonance frequency but also on the density of the solution. As a result, the following empirical correlation, more practical than Eq. 9, is used as calibration curve for the TQV viscometer:

$$
\mu(f, T, \rho) \rightarrow \ln (\mu / m P a s)=A+\frac{B}{T}+C * f+D * f^{6}+E / \rho
$$

Where $\mu$ is the viscosity in mPas, $T$ is the temperature in Kelvin, $f$ is the resonance frequency $(\mathrm{Hz})$ of the vibrating quartz cell and $\rho$ is the density in $\mathrm{gcm}^{-3}, \ln$ represents the natural logarithm.

The model includes numerical coefficients $(A-B-C-D-E)$ which are fitted using the viscosity data measured with the falling ball viscometer related to unloaded LysK solutions (presented in 2.4): the resonance frequency is measured for unloaded solutions ( $4.44 \mathrm{~m}, 4.21 \mathrm{~m}, 2.16 \mathrm{~m}, 2.14 \mathrm{~m}$ LysK molality) under the same conditions reported in Table 4 (left column) and, via linear regression against the experimental viscosity, the values of the model parameters $(A-B-C-D-E$ ) which minimise the deviation between the model and the data are obtained; these values are reported in Table 5 with the standard deviations.

The pressure transducers have been calibrated against a PACE 5000 Modular Pressure Calibrator (GE Sensing France). The accuracy of the pressure transducer is $\pm 0.0002 \mathrm{MPa}$. The viscometer cell temperature is measured by one four-wire Pt100 Platinum Resistance Thermometer probe calibrated against a reference four-wire PT-25 Platinum Resistance Thermometer probe (PT-100). The $25 \Omega$ reference platinum resistance thermometer (TINSLEY Precision Instruments) was calibrated by the Laboratoire National d'Essais (Paris) based on the 1990 International Temperature Scale (ITS 90). The results accuracy for temperature is not higher than $\pm 0.03 \mathrm{~K}$.

Once the relationship between the resonance frequency of the quartz crystal and the viscosity of the liquid is established, it is then possible to measure the resonance frequency of a $\mathrm{CO}_{2}$ loaded LysK solution and to convert it into the corresponding value of viscosity via this correlation. The density of $\mathrm{CO}_{2}$-loaded solutions is evaluated with a suitable empirical correlation, previously calibrated on volumetric measurements made available by the Anton Paar densimeter (see Section 4 for more details). 
The accuracy of the calibrated model of the TQV (i.e., Eq. 10), expressed as the capability to reproduce the experimental data obtained from the falling ball viscometer is highlighted in the parity plot in Figure 3 (reporting the matching between the experimental data and the model results) and in SI paragraph 3. As it is displayed in Figure 3 and Figure S1 (plot of residual), once the resonance frequency of the quartz sensor, the temperature of the system and the density of the solution are known, the model can provide accurate results. For the entire range of frequencies tested, the maximum absolute value reached by the residual function, defined as the absolute deviation between the experimental viscosity and the calculated one, is $0.06 \mathrm{mPas}$ (for experimental results ranging from 0.96 to $7.60 \mathrm{mPas}$ ).

Table S1 in SI paragraph 3 summarises the numerical values of the quantities (density and viscosities) and parameters (frequency) used to calibrate the coefficients of Eq. 10, and, for each test condition, it compares the values of experimental viscosity (from the falling ball viscometer) vs the ones calculated with the calibrated model.

Since the viscosity values for $\mathrm{CO}_{2}$ loaded LysK solution are derived from a semi empirical correlation that reproduces a calibration curve of the quartz viscometer, the sources of uncertainty will be of different nature. They include: (i) the accuracy of the calibration performed (deviation between experimental data and model results), (ii) the intrinsic uncertainty of the experimental values used for the calibration and (iii) the uncertainty linked to the standard deviation of the model parameters of Eq. 10. A more detailed analysis on the uncertainty determination is given in SI paragraph 4.

Table 5: Values of the model coefficients used for the calibration of the Flucon QVis quartz viscometer.

\begin{tabular}{|c|c|c|c|c|c|}
\hline & A & $B$ [K] & $\mathrm{C}\left[\mathrm{Hz}^{-1}\right]$ & $\operatorname{Dx} 10^{7}\left[\mathrm{~Hz}^{-6}\right]$ & $E$ \\
\hline Values & 14.54 & 1228.76 & -0.28 & 7.17 & -17.07 \\
\hline Std. Deviation & 0.33 & 109.71 & 0.04 & 2.43 & 0.48 \\
\hline
\end{tabular}

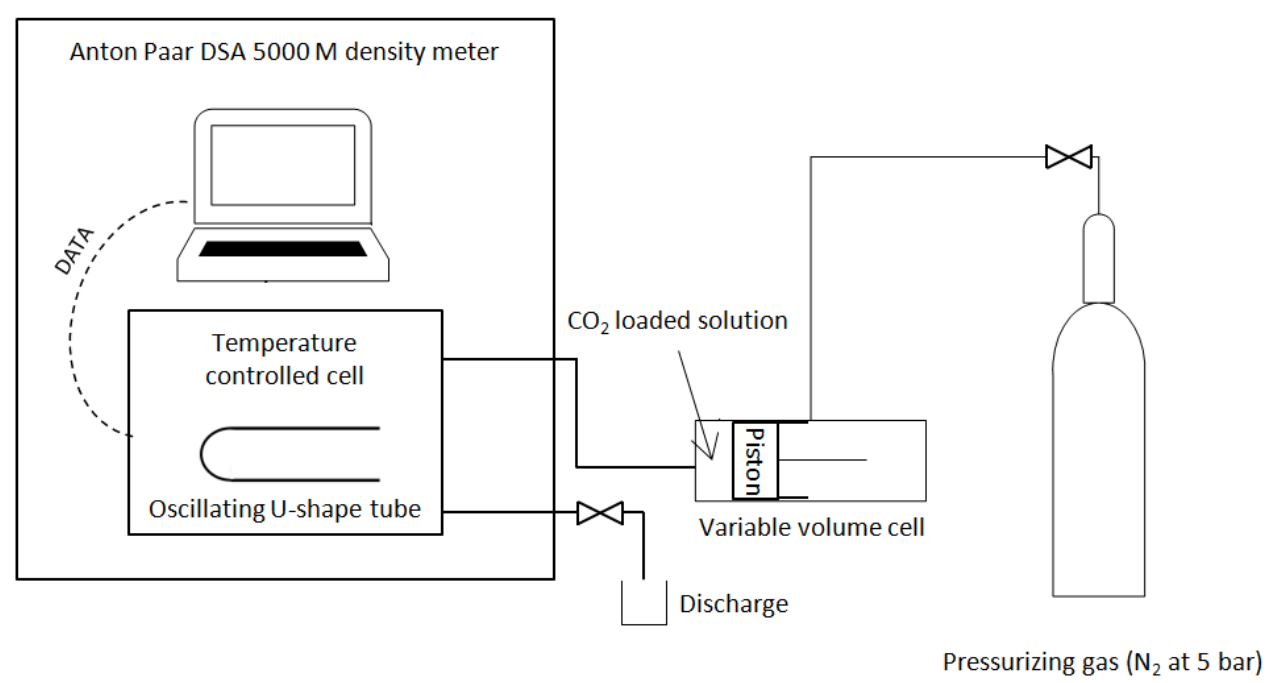

Figure 1: Scheme of the connection employed to charge the $\mathrm{CO}_{2}$ loaded solvent in the Anton Paar DSA $5000 \mathrm{M}$ density meter 


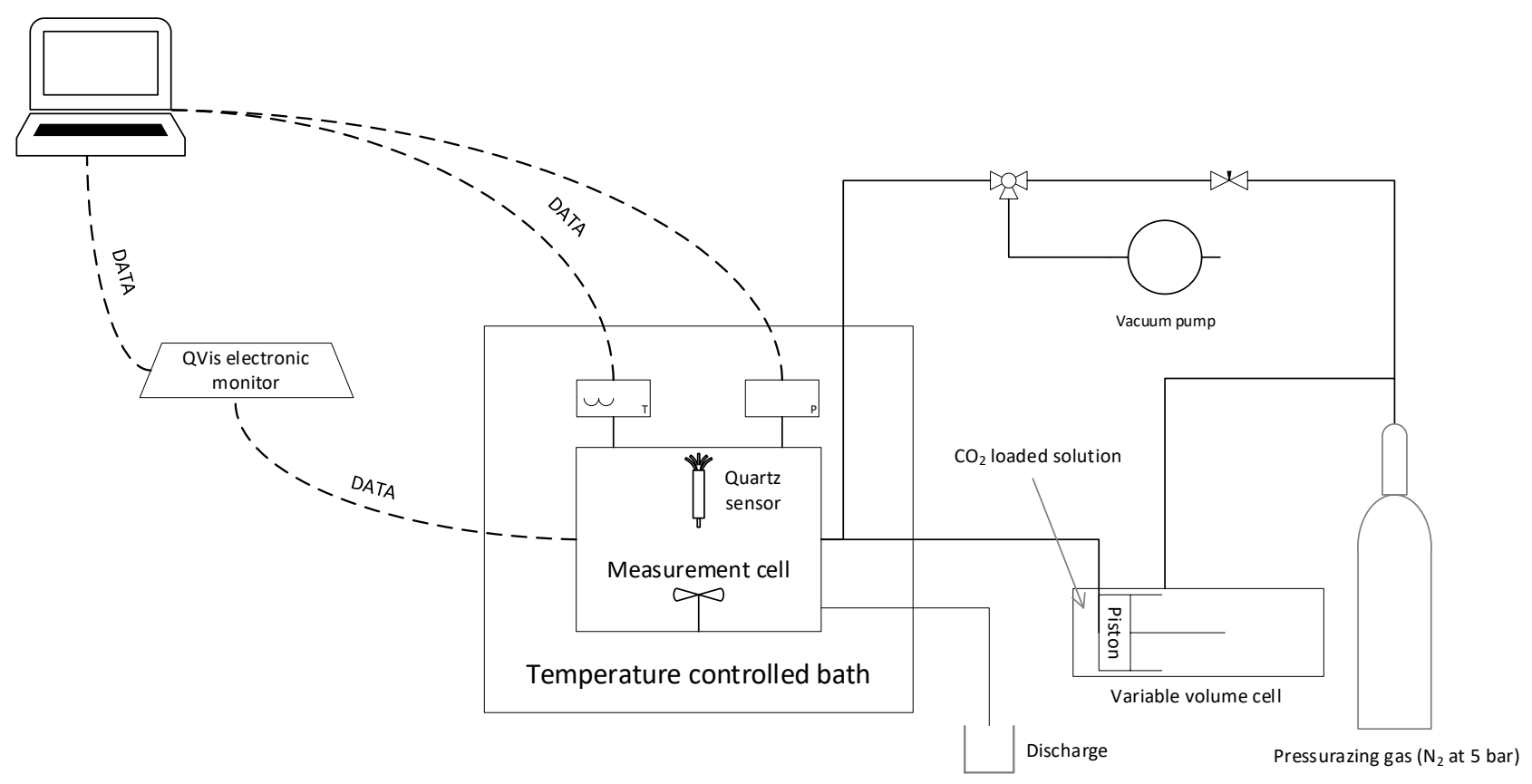

Figure 2: Scheme of the vibrating quartz viscometer (Flucon QVis 01/L) test bench.

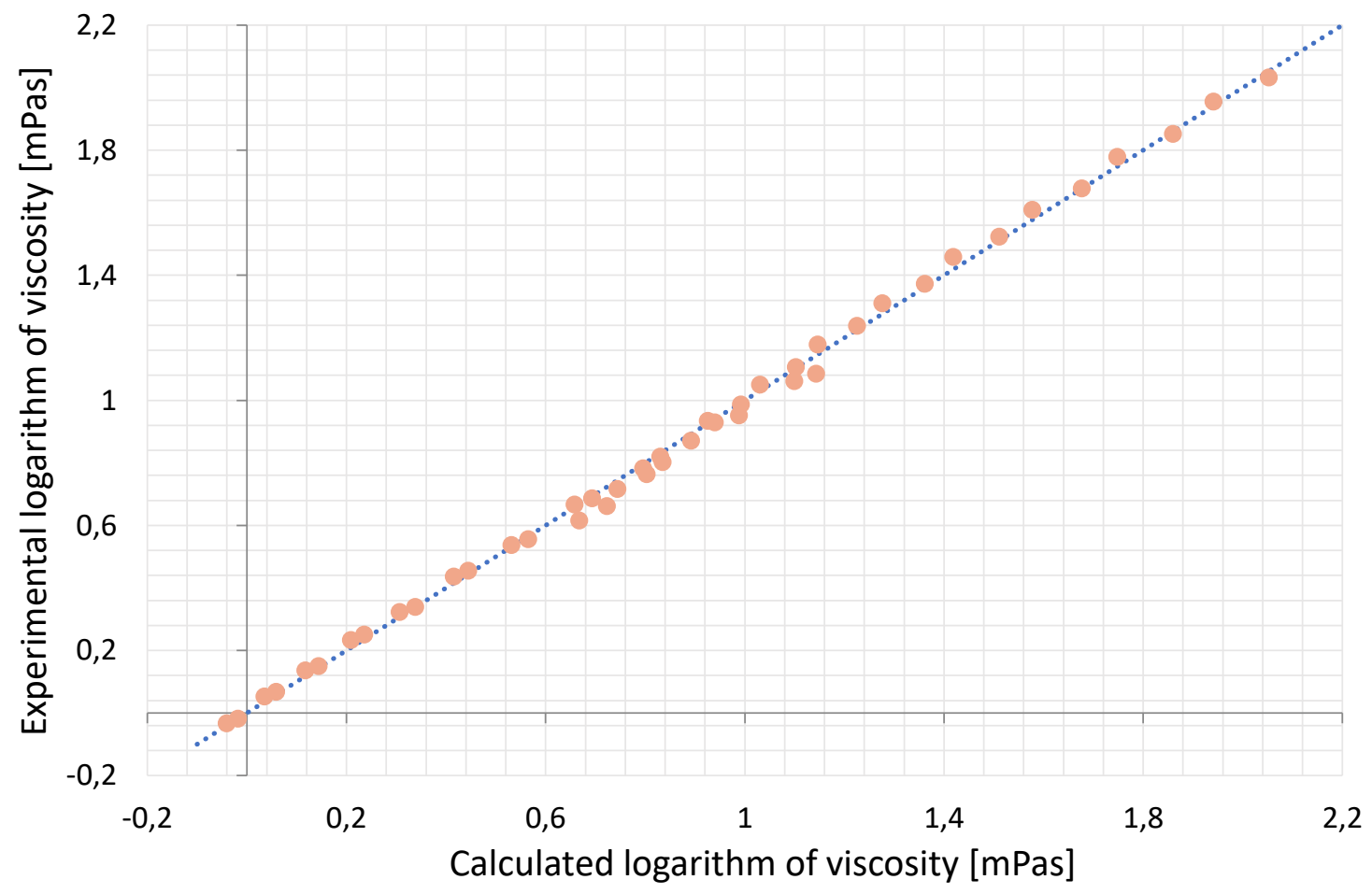

Figure 3: Parity plot reporting on the x-axis the logarithmic values of the viscosity for the unloaded LysK solutions calculated by the model for the frequency - viscosity relationship (Eq. 10), and on the y-axis the experimental data obtained with the LOVIS 2000 ME.

\section{Experimental results}

In this section, the numerical values of densities and viscosities obtained during the experimental campaigns are presented, both for unloaded and for $\mathrm{CO}_{2}$ loaded LysK solutions, and they are associated to the corresponding uncertainty values $(u)$. 


\subsection{Density and viscosity of unloaded LysK solutions - Experimental data}

The measured thermophysical properties of unloaded LysK solution are reported in Table 6 and Table 7. These data refer to three different measurement cycles of densities and viscosities inside the temperature range of $288.15-343.15 \mathrm{~K}$ (with a $5 \mathrm{~K}$ step), and for the five values of LysK concentration in the solutions indicated in paragraph 2.2. The uncertainty on the experimental data is calculated as a combination of a type $A$ and a type B uncertainty (see paragraph 5 of the SI file for more information).

\subsection{Density and viscosity of $\mathrm{CO}_{2}$ loaded LysK solutions - Experimental data}

Experimental data of density and viscosity for the loaded solutions are reported in Table 8 and Table 9 for each value of temperature tested and at the various $\mathrm{CO}_{2}$ content in the solution reached. Density measurements of $\mathrm{CO}_{2}$ loaded solutions were only performed once, so statistical dispersion is simply attributable to instrument accuracy (type B uncertainty). Uncertainty on viscosity is calculated with the formula for the combined standard uncertainty reported in ${ }^{28}$, which combines the uncertainty related with the falling ball viscometer, the one coming from the frequency - viscosity calibration and the standard deviations of the model parameters. The uncertainty on the $\mathrm{CO}_{2}$ loading achieved is equal to 0.05 molCO $2 /$ molLysK and it is the same for all the loadings obtained. It is determined following the procedure explained in paragraph 3 of the SI file.

Table 6: Experimental measurements for density of unloaded LysK solutions (concentration level expressed in molality $m$ ) \pm the corresponding calculated uncertainty values $(u(\rho))$ at the five different LysK concentration levels in the temperature range $T=(288.15$ to 343.15) $\mathrm{K}$ at $0.1013 \mathrm{MPa} . \boldsymbol{u}(T)$ and $\boldsymbol{u}(P)$ represent respectively the standard uncertainty on the temperature and pressure at which the measurements have been carried out.

Experimental densities of unloaded LysK solutions $\left[\mathrm{gcm}^{-3}\right]$ and combined standard uncertainty $\left[\mathrm{gcm}^{-3}\right]$

\begin{tabular}{cccccc}
\hline \multirow{2}{*}{ Temperature $[K]$} & \multicolumn{5}{c}{ LysK molality in the aqueous solution $(\mathrm{m})$} \\
\cline { 2 - 6 } & $2.16 \mathrm{~m}$ & $2.93 \mathrm{~m}$ & $3.65 \mathrm{~m}$ & $4.21 \mathrm{~m}$ & $4.44 \mathrm{~m}$ \\
\hline 288.15 & $1.10570 \pm 0.00006$ & $1.12801 \pm 0.00008$ & $1.14571 \pm 0.00010$ & $1.15765 \pm 0.00002$ & $1.16165 \pm 0.00051$ \\
\hline 293.15 & $1.10076 \pm 0.00006$ & $1.12274 \pm 0.00008$ & $1.14034 \pm 0.00018$ & $1.15187 \pm 0.00013$ & $1.15594 \pm 0.00052$ \\
\hline 298.15 & $1.09616 \pm 0.00006$ & $1.11789 \pm 0.00010$ & $1.13516 \pm 0.00010$ & $1.14682 \pm 0.00002$ & $1.15073 \pm 0.00050$ \\
\hline 303.15 & $1.09190 \pm 0.00006$ & $1.11337 \pm 0.00008$ & $1.13041 \pm 0.00009$ & $1.14199 \pm 0.00001$ & $1.14585 \pm 0.00051$ \\
\hline 308.15 & $1.08797 \pm 0.00006$ & $1.10926 \pm 0.00008$ & $1.12618 \pm 0.00010$ & $1.13762 \pm 0.00002$ & $1.14146 \pm 0.00050$ \\
\hline 313.15 & $1.08439 \pm 0.00006$ & $1.10547 \pm 0.00008$ & $1.12221 \pm 0.00008$ & $1.13360 \pm 0.00001$ & $1.13740 \pm 0.00050$ \\
\hline 318.15 & $1.08115 \pm 0.00006$ & $1.10210 \pm 0.00008$ & $1.11876 \pm 0.00010$ & $1.13003 \pm 0.00001$ & $1.13382 \pm 0.00049$ \\
\hline 323.15 & $1.07825 \pm 0.00006$ & $1.09906 \pm 0.00008$ & $1.11558 \pm 0.00008$ & $1.12681 \pm 0.00001$ & $1.13057 \pm 0.00050$ \\
\hline 328.15 & $1.07569 \pm 0.00006$ & $1.09641 \pm 0.00008$ & $1.11288 \pm 0.00010$ & $1.12404 \pm 0.00001$ & $1.12779 \pm 0.00049$ \\
\hline 333.15 & $1.07348 \pm 0.00006$ & $1.09410 \pm 0.00008$ & $1.11048 \pm 0.00008$ & $1.12162 \pm 0.00001$ & $1.12535 \pm 0.00049$ \\
\hline 338.15 & $1.07159 \pm 0.00006$ & $1.09216 \pm 0.00008$ & $1.10852 \pm 0.00009$ & $1.11961 \pm 0.00001$ & $1.12334 \pm 0.00049$ \\
\hline 343.15 & $1.07005 \pm 0.00006$ & $1.09058 \pm 0.00008$ & $1.10691 \pm 0.00009$ & $1.11798 \pm 0.00001$ & $1.12171 \pm 0.00049$ \\
\hline Standard uncertainty $\boldsymbol{u}(\mathrm{T})=0.02 \mathrm{~K} \boldsymbol{u}(\mathrm{P})=0.04 \mathrm{kPa}$ & & & &
\end{tabular}

Table 7: Experimental measurements for viscosity of unloaded LysK solutions (concentration level expressed in molality $m$ ) \pm the corresponding calculated uncertainty values $(u(\mu))$ at the five different LysK concentration levels in the temperature range $T=(288.15$ to 343.15) $K$ at $0.1013 \mathrm{MPa} . \boldsymbol{u}(T)$ and $\boldsymbol{u}(P)$ represent respectively the standard uncertainty on the temperature and pressure at which the measurements have been carried out.

Experimental viscosities of unloaded LysK solutions [mPas] and combined standard uncertainty [mPas]

\begin{tabular}{llllll}
\hline \multirow{2}{*}{ Temperature $[\mathrm{K}]$} & \multicolumn{5}{c}{ LysK molality in the aqueous solution $(\mathrm{m})$} \\
\cline { 2 - 4 } & $2.16 \mathrm{~m}$ & $2.93 \mathrm{~m}$ & $3.65 \mathrm{~m}$ & $4.21 \mathrm{~m}$ & $4.44 \mathrm{~m}$ \\
\hline
\end{tabular}




\begin{tabular}{llllll}
\hline 288.15 & $3.5141 \pm 0.0155$ & $4.9793 \pm 0.0210$ & $6.8547 \pm 0.0181$ & $8.6159 \pm 0.0594$ & $9.4155 \pm 0.0243$ \\
\hline 293.15 & $2.9607 \pm 0.0107$ & $4.1768 \pm 0.0140$ & $5.6832 \pm 0.0129$ & $7.0665 \pm 0.0493$ & $7.6383 \pm 0.0170$ \\
\hline 298.15 & $2.5899 \pm 0.0089$ & $3.5761 \pm 0.0142$ & $4.8060 \pm 0.0096$ & $5.9217 \pm 0.0416$ & $6.3786 \pm 0.0127$ \\
\hline 303.15 & $2.2325 \pm 0.0080$ & $3.0740 \pm 0.0101$ & $4.0859 \pm 0.0073$ & $4.9991 \pm 0.0363$ & $5.3590 \pm 0.0096$ \\
\hline 308.15 & $1.9887 \pm 0.0083$ & $2.6868 \pm 0.0107$ & $3.5374 \pm 0.0057$ & $4.2989 \pm 0.0318$ & $4.5942 \pm 0.0078$ \\
\hline 313.15 & $1.7445 \pm 0.0081$ & $2.3526 \pm 0.0078$ & $3.0718 \pm 0.0048$ & $3.7090 \pm 0.0295$ & $3.9492 \pm 0.0062$ \\
\hline 318.15 & $1.5773 \pm 0.0085$ & $2.0918 \pm 0.0077$ & $2.7099 \pm 0.0052$ & $3.2508 \pm 0.0326$ & $3.4531 \pm 0.0069$ \\
\hline 323.15 & $1.4043 \pm 0.0094$ & $1.8611 \pm 0.0058$ & $2.3941 \pm 0.0064$ & $2.8578 \pm 0.0356$ & $3.0252 \pm 0.0088$ \\
\hline 328.15 & $1.2858 \pm 0.0113$ & $1.6756 \pm 0.0060$ & $2.1432 \pm 0.0085$ & $2.5455 \pm 0.0413$ & $2.6870 \pm 0.0113$ \\
\hline 333.15 & $1.1617 \pm 0.0139$ & $1.5117 \pm 0.0049$ & $1.9206 \pm 0.0105$ & $2.2712 \pm 0.0500$ & $2.3927 \pm 0.0151$ \\
\hline 338.15 & $1.0709 \pm 0.0177$ & $1.3766 \pm 0.0045$ & $1.7379 \pm 0.0152$ & $2.0476 \pm 0.0590$ & $2.1497 \pm 0.0213$ \\
\hline 343.15 & $0.9819 \pm 0.0231$ & $1.2560 \pm 0.0040$ & $1.5780 \pm 0.0232$ & $1.8516 \pm 0.0880$ & $1.9407 \pm 0.0300$ \\
\hline
\end{tabular}

Standard uncertainty $\boldsymbol{u}(\mathrm{T})=0.02 \mathrm{~K} \boldsymbol{u}(\mathrm{P})=0.04 \mathrm{kPa}$

Table 8: Experimental measurements for density of $\mathrm{CO}_{2}$ loaded solutions at $4.21 \mathrm{~m} \mathrm{LysK}$ concentration \pm the corresponding calculated uncertainty values $(u(\rho))$ at the four different $\mathrm{CO}_{2}$ in solution in the temperature range $T=(293.15$ to 358.15$) \mathrm{K}$ at $0.1013 \mathrm{MPa}$. $\boldsymbol{u}(T)$ and $\boldsymbol{u}(P)$ represent respectively the standard uncertainty on the temperature and pressure at which the measurements have been carried out.

\section{Experimental densities of $\mathrm{CO}_{2}$ loaded LysK solutions $\left[\mathrm{gcm}^{-3}\right]$ and combined standard uncertainty $\left[\mathrm{gcm}^{-3}\right]$}

\begin{tabular}{ccccc}
\hline \multirow{2}{*}{ Temperature $[\mathrm{K}]$} & \multicolumn{4}{c}{$\mathrm{CO}_{2}$ Loading, $\alpha[\mathrm{molCO} / \mathrm{mo} / \mathrm{LysK}]$} \\
\cline { 2 - 5 } & 0.29 & 0.49 & 0.78 & 0.98 \\
\hline 293.15 & $1.17321 \pm 0.00005$ & $1.19167 \pm 0.00005$ & $1.21787 \pm 0.00005$ & $1.22618 \pm 0.00005$ \\
\hline 298.15 & $1.17065 \pm 0.00005$ & $1.18908 \pm 0.00005$ & $1.21525 \pm 0.00005$ & $1.22353 \pm 0.00005$ \\
\hline 303.15 & $1.16802 \pm 0.00005$ & $1.18658 \pm 0.00005$ & $1.21256 \pm 0.00005$ & $1.22080 \pm 0.00005$ \\
\hline 308.15 & $1.16535 \pm 0.00005$ & $1.18384 \pm 0.00005$ & $1.20989 \pm 0.00005$ & $1.21813 \pm 0.00005$ \\
\hline 313.15 & $1.16261 \pm 0.00005$ & $1.18119 \pm 0.00005$ & $1.20709 \pm 0.00005$ & $1.21534 \pm 0.00005$ \\
\hline 318.15 & $1.15981 \pm 0.00005$ & $1.17837 \pm 0.00005$ & $1.20437 \pm 0.00005$ & $1.21259 \pm 0.00005$ \\
\hline 323.15 & $1.15695 \pm 0.00005$ & $1.17554 \pm 0.00005$ & $1.20153 \pm 0.00005$ & $1.20977 \pm 0.00005$ \\
\hline 328.15 & $1.15403 \pm 0.00005$ & $1.17268 \pm 0.00005$ & $1.19870 \pm 0.00005$ & $1.20692 \pm 0.00005$ \\
\hline 333.15 & $1.15105 \pm 0.00005$ & $1.16970 \pm 0.00005$ & $1.19580 \pm 0.00005$ & $1.20400 \pm 0.00005$ \\
\hline 338.15 & $1.14802 \pm 0.00005$ & $1.16678 \pm 0.00005$ & $1.19286 \pm 0.00005$ & $1.20107 \pm 0.00005$ \\
\hline 343.15 & $1.14493 \pm 0.00005$ & $1.16369 \pm 0.00005$ & $1.18985 \pm 0.00005$ & $1.19795 \pm 0.00005$ \\
\hline 348.15 & $1.14178 \pm 0.00005$ & $1.16069 \pm 0.00005$ & $1.18681 \pm 0.00005$ & $1.19488 \pm 0.00005$ \\
\hline 353.15 & $1.13854 \pm 0.00005$ & $1.15754 \pm 0.00005$ & $1.18368 \pm 0.00005$ & $1.19157 \pm 0.00005$ \\
\hline 358.15 & $1.13521 \pm 0.00005$ & $1.15436 \pm 0.00005$ & $1.18048 \pm 0.00005$ & $1.18835 \pm 0.00005$ \\
\hline
\end{tabular}

Standard uncertainty $\boldsymbol{u}(\mathrm{T})=0.02 \mathrm{~K} \boldsymbol{u}(\mathrm{P})=0.04 \mathrm{kPa} \boldsymbol{u}(\alpha)=0.05 \mathrm{molCO}_{2} / \mathrm{molLysK}$

Table 9: Experimental measurements for viscosity of $\mathrm{CO}_{2}$ loaded solutions at $4.21 \mathrm{~m}$ LysK concentration \pm the corresponding calculated uncertainty values $(u(\mu))$ at the three different $\mathrm{CO}_{2}$ loadings in solution in the temperature range $\mathrm{T}=(293.15$ to 343.15$) \mathrm{K}$ at $0.5 \mathrm{MPa}$. $\boldsymbol{u}(T)$ and $\boldsymbol{u}(P)$ represent respectively the standard uncertainty on the temperature and pressure at which the measurements have been carried out.

\begin{tabular}{cccc}
\hline \multicolumn{4}{c}{ Experimental viscosities of $\mathrm{CO}_{2}$ loaded LysK solutions [mPas] and combined standard } \\
uncertainty [mPas]
\end{tabular}




\begin{tabular}{cccc}
\hline $293.15 K$ & $19.43 \pm 0.69$ & $27.29 \pm 0.69$ & $32.75 \pm 0.68$ \\
\hline $298.15 K$ & $16.49 \pm 0.69$ & $22.08 \pm 0.69$ & $26.65 \pm 0.68$ \\
\hline $303.15 K$ & $13.61 \pm 0.69$ & $18.01 \pm 0.69$ & $21.69 \pm 0.69$ \\
\hline $308.15 K$ & $11.47 \pm 0.69$ & $15.09 \pm 0.69$ & $17.87 \pm 0.69$ \\
\hline $313.15 K$ & $9.70 \pm 0.70$ & $12.43 \pm 0.69$ & $14.98 \pm 0.69$ \\
\hline $318.15 K$ & $8.34 \pm 0.70$ & $10.56 \pm 0.69$ & $12.76 \pm 0.69$ \\
\hline $323.15 K$ & $7.16 \pm 0.70$ & $9.05 \pm 0.69$ & $10.93 \pm 0.69$ \\
\hline $328.15 K$ & $6.19 \pm 0.70$ & $7.67 \pm 0.70$ & $9.51 \pm 0.69$ \\
\hline $333.15 K$ & $5.43 \pm 0.70$ & $6.78 \pm 0.70$ & $8.30 \pm 0.70$ \\
\hline $338.15 K$ & $4.84 \pm 0.70$ & $5.88 \pm 0.70$ & $7.32 \pm 0.70$ \\
\hline $343.15 K$ & $4.29 \pm 0.70$ & $5.24 \pm 0.70$ & $6.53 \pm 0.70$ \\
\hline Standard uncertainty $\boldsymbol{u}(\mathrm{T})=0.03 \mathrm{~K} \boldsymbol{u}(\mathrm{P})=0.02 \mathrm{kPa} \boldsymbol{u}(\alpha)=0.05 \mathrm{molCO} \mathrm{CO}_{2} / \mathrm{molLysK}$
\end{tabular}

\section{Modelling approaches}

\subsection{Density of unloaded LysK solutions}

To propose a suitable correlation to interpolate the density of unloaded LysK solutions as a function of temperature and concentration, the modified form of the empirical equation by Graber [30] is employed. It is an empirical correlation that has been already applied with good accuracy to other amino acid salts solutions, like $\alpha$-aminobutyric acid, $\alpha$-alanine, L-phenylalanine, serine ${ }^{29-32}$. The equation is the following:

$$
\rho\left[\mathrm{gcm}^{-3}\right]=\exp \left(A_{1}+A_{2} * T^{0.5}+A_{3} * w_{0}^{0.5}\right)+A_{4}+A_{5} * w_{\%}^{0.5}
$$

Where $\rho$ is the density, $T$ is the absolute temperature $[K], w_{\%}$ is the mass fraction (\% w/w) of LysK and $A_{j}$ ( $\mathrm{j}$ $=1$ to 5 ) are the correlation parameters. The latters have been obtained by fitting the experimental data (60 points) with the equation above using the linear least square regression of the function Isqcurvefit in MATLAB $^{\circledR}$ (version R2020b). They are listed in Table 10 with the corresponding standard deviation. The procedure to determine the standard deviation of the model parameters is explained in paragraph 4 of the SI file. In addition, the table reports statistical parameters which can give an indication on the performance of the model in reproducing the experimental data.

Table 10: Model parameters for the Graber equation with their relative standard deviations and relative statistical errors of the correlation. $R^{2}$ is the coefficient of the determination, $A R D$ is the average relative deviation $\left(\frac{1}{N} * \sum_{i=1}^{N}\left|\frac{\rho_{\exp }-\rho_{\text {calc }}}{\rho_{\text {exp }}}\right|\right)$ and $A A D$ is the average absolute deviation $\left(\frac{1}{N} * \sum_{i=1}^{N}\left|\rho_{\text {exp }}-\rho_{\text {calc }}\right|\right)$.

\begin{tabular}{cccccccc}
\hline & $\mathbf{A}_{\mathbf{1}}$ & $\mathbf{A}_{\mathbf{2}}$ & $\mathbf{A}_{\mathbf{3}} \times \mathbf{1 0}^{\mathbf{2}}$ & $\mathbf{A}_{\mathbf{4}}$ & $\mathbf{A}_{5} \times \mathbf{1 0}^{\mathbf{2}}$ & $\mathbf{R}^{\mathbf{2}}$ & 0.9993 \\
\hline Values & 8.56 & -0.71 & 9.29 & 0.86 & 3.56 & ARD [\%] & 0.0485 \\
\hline Std. Deviation & 0.52 & 0.03 & 1.33 & 0.01 & 0.05 & AAD [gcm-3] & 0.00054
\end{tabular}

\subsection{Viscosity of unloaded LysK solutions}

The Modified Vogel-Tamman-Fulcher (VTF) equation has been applied for a large number of amino acid salts solutions ${ }^{29-32}$ to model the viscosity of unloaded solutions as a function of temperature and AAS concentration. The model can be considered as an Arrhenius type asymptotic exponential function, where a second order temperature-dependent term is added to account for the characteristic behaviour of ionic systems ${ }^{32}$ : 


$$
\mu[m P a s]=\exp \left(A_{0}+\frac{A_{1}}{T}+\frac{A_{2}}{T^{2}}\right)
$$

As it is reported in the abovementioned works ${ }^{29-32}$, the $A_{j}$ parameters are assumed to be concentrationdependent. This approach has demonstrated higher accuracy in viscosity interpolation for different concentration values of the tested potassium lysinate solutions. As a result, the modified VTF equation becomes:

$$
\ln (\mu / m P a s)=\left(b_{1}+b_{2} w_{\%}+b_{3} w_{\%}^{2}\right)+\frac{\left(b_{4}+b_{5} w_{\%}+b_{6} w_{\%}^{2}\right)}{T}+\frac{\left(b_{7}+b_{8} w_{\%}+b_{9} w_{\%}^{2}\right)}{T^{2}}
$$

Where $w_{\%}$ is the mass fraction of the amino acid salt. The parameters indicated as $b_{4}$ and $b_{9}$ showed little statistical representativeness in terms of model accuracy and performances. Thus, Eq. 13 can be simplified, as reported in Eq. 14:

$$
\ln (\mu / m P a s)=\left(b_{1}+b_{2} * w_{\%}+b_{3} * w_{\%}^{2}\right)+\frac{\left(b_{4} * w_{\%}+b_{5} * w_{\%}^{2}\right)}{T}+\frac{\left(b_{6}+b_{7} * w_{\%}\right)}{T^{2}}
$$

The model parameters are obtained from linear least square regression in MATLAB ${ }^{\circledR}$ (version R2020b) against the experimental data ( 60 points), using the Isqcurvefit function. The model parameters are reported in Table 11 together with their standard deviations.

Table 11: Values and standard deviations of the modified VTF parameters. Additional statistical errors of the correlation are reported

\begin{tabular}{|c|c|c|c|c|c|c|c|}
\hline & $b_{1}$ & $b_{2}$ & $b_{3} \times 10^{2}$ & $b_{4} \times 10^{-2}$ & $b_{5}$ & $b_{6} \times 10^{-5}$ & $b_{7} \times 10^{-5}$ \\
\hline Values & -3.38 & 0.17 & -0.10 & -0.97 & 0.43 & 2.99 & 0.15 \\
\hline Std. Deviation & 0.29 & 0.02 & 0.04 & 0.07 & 0.14 & 0.29 & 0.01 \\
\hline $\mathbf{R}^{2}$ & 0.9999 & & & & & & \\
\hline ARD [\%] & 0.46 & & & & & & \\
\hline AAD [gcm-3] & 0.0148 & & & & & & \\
\hline
\end{tabular}
in the table: $R^{2}$ is the coefficient of the determination, $A R D$ is the average relative deviation $\left(\frac{1}{N} * \sum_{i=1}^{N}\left|\frac{\mu_{\exp }-\mu_{\text {calc }}}{\mu_{\exp }}\right|\right)$ and $A A D$ is the average absolute deviation $\left(\frac{1}{N} * \sum_{i=1}^{N}\left|\mu_{\text {exp }}-\mu_{\text {calc }}\right|\right)$.

\subsection{Correlation for density of $\mathrm{CO}_{2}$-loaded LysK solutions}

Experimental densities of the $\mathrm{CO}_{2}$-loaded solutions have been correlated with the following equation:

$$
\rho\left[\mathrm{gcm}^{-3}\right]=K_{0}+K_{1} * \alpha_{\mathrm{CO} 2}+K_{2} *\left(\alpha_{\mathrm{CO} 2}\right)^{2}+K_{3} * T
$$

Where $K_{0}, K_{1}, K_{2}$ are the model parameters (Table 12 ), $\alpha_{\mathrm{CO} 2}$ is the $\mathrm{CO}_{2}$ loading in $\mathrm{molCO}_{2} / \mathrm{molLysK}$ and $T$ is the temperature $[\mathrm{K}]$.

The correlation was first proposed by Shen et al. ${ }^{16}$, and in the present paper we have modified it introducing a second order $\mathrm{CO}_{2}$ loading dependent term that has been shown to improve the accuracy of the model and to better correlate experimental data. An equation able to model the density of $\mathrm{CO}_{2}$ loaded solutions for a wide range of loadings and temperatures is necessary also to calculate the viscosity from the correlation developed between the resonance frequency of the quartz viscometer and the viscosity of the solution under investigation, as outlined in paragraph 2.5. Thanks to this correlation, it is possible to calculate, with reasonable accuracy, the density of LysK solutions at $\mathrm{CO}_{2}$ loading values different from the ones tested experimentally, as in the case of the samples used to calculate the viscosity of $\mathrm{CO}_{2}$ loaded solutions. 
Table 12: Values and standard deviations of the parameter used to correlate the density of $\mathrm{CO}_{2}$ loaded LysK solutions. Additional statistical errors of the correlation are reported in the table: $R^{2}$ is the coefficient of the determination, ARD is the average relative deviation $\left(\frac{1}{N} * \sum_{i=1}^{N}\left|\frac{\rho_{\text {exp }}-\rho_{\text {calc }}}{\rho_{\text {exp }}}\right|\right)$ and $A A D$ is the average absolute deviation $\left(\frac{1}{N} * \sum_{i=1}^{N}\left|\rho_{\text {exp }}-\rho_{\text {calc }}\right|\right)$.

\begin{tabular}{ccccccc}
\hline & $\mathrm{K}_{\mathbf{0}}$ & $\mathrm{K}_{\mathbf{1}}$ & $\mathrm{K}_{\mathbf{2}}$ & $\mathbf{K}_{3} \times 10^{3}$ & $\mathbf{R}^{2}$ & 0.9972 \\
\hline Values & 1.315 & 0.118 & -0.033 & -0.584 & ARD [\%] & 0.13 \\
\hline Std. Deviation & 0.003 & 0.002 & 0.002 & 0.010 & $\begin{array}{c}\text { AAD } \\
{\left[\mathrm{gcm}^{-3}\right]}\end{array}$ & 0.00148 \\
\hline
\end{tabular}

\subsection{Correlation for viscosity of $\mathrm{CO}_{2}$-loaded LysK solutions}

A similar correlation is applied to the viscosity values for $\mathrm{CO}_{2}$ loaded LysK solutions, and it is presented below in Eq.16. It is a modification of the correlation proposed by Shen in the already mentioned work ${ }^{16}$, since an additional quadratic term describing the dependence of viscosity on $\mathrm{CO}_{2}$ loading has been added to improve the fitting, with the same approach used for density. The temperature-dependent term of the viscosity model is a derivation of the Arrhenius equation. This model will be helpful for predicting the viscosity in the $\mathrm{CO}_{2}$ loading and temperature ranges tested.

$$
\ln (\mu / m P a s)=a+\frac{b}{T}+c * \alpha_{C O 2}+d *\left(\alpha_{C O 2}\right)^{2}
$$

Table 13: Values and standard deviations of the parameter used to correlate the viscosity of $\mathrm{CO}_{2}$ loaded LysK solutions. Additional statistical errors of the correlation are reported in the table: $R^{2}$ is the coefficient of the determination, ARD is the average relative deviation $\left(\frac{1}{N} * \sum_{i=1}^{N}\left|\frac{\mu_{\text {exp }}-\mu_{\text {calc }}}{\mu_{\text {exp }}}\right|\right)$ and $A A D$ is the average absolute deviation $\left(\frac{1}{N} * \sum_{i=1}^{N}\left|\mu_{\text {exp }}-\mu_{\text {calc }}\right|\right)$.

\begin{tabular}{ccccccc}
\hline & a & b & c & d & $\mathbf{R}^{2}$ & $\begin{array}{c}0.99 \\
46\end{array}$ \\
\hline Values & -8.48 & 3079.91 & 3.40 & -2.12 & ARD [\%] & 2.76 \\
\hline Std. Deviation & 0.17 & 52.85 & 0.09 & 0.11 & AAD $\left[\mathrm{gcm}^{-3}\right]$ & 0.04 \\
\hline
\end{tabular}

\section{Discussion}

In the context of experimental research on thermodynamic and physical properties for pure substances or mixtures, it is always a good practice to compare the results obtained with the literature values when available. The measurements carried out in this work on unloaded LysK solutions have been compared with the literature data taken from the works of Bian et al. ${ }^{18}$ and Suleman et al. ${ }^{20}$, and the results are plotted in Figure 4 and Figure 5. The diagrams reflect the fact that there exist still significant deviations between the data reported. However, when comparing solution with an equal LysK concentration ( $3.65 \mathrm{~mol} \mathrm{LysK}_{\mathrm{K}} / \mathrm{kg}_{\text {water }}$ ) the maximum relative percentage error calculated is $1.16 \%$ for density and $14.5 \%$ for viscosity, therefore providing indications of a good accordance between the sets of data. 


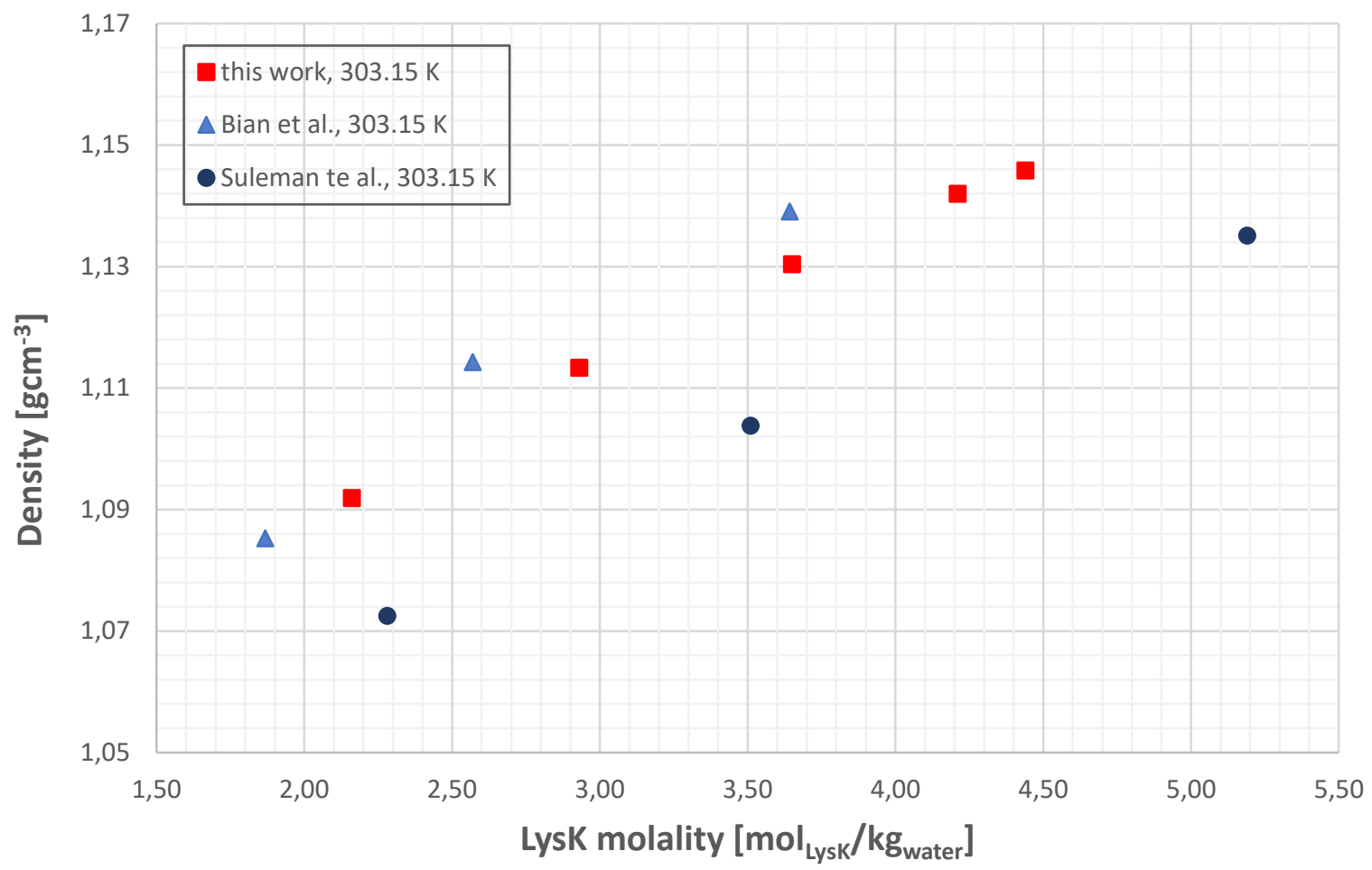

Figure 4: Comparison of experimental data on density at 303.15 $\mathrm{K}$ of LysK solution at various molality concentrations ( $\square$ this work, $\Delta$ Bian et al. ${ }^{18}$, o Suleman et al. $\left.{ }^{20}\right)$.

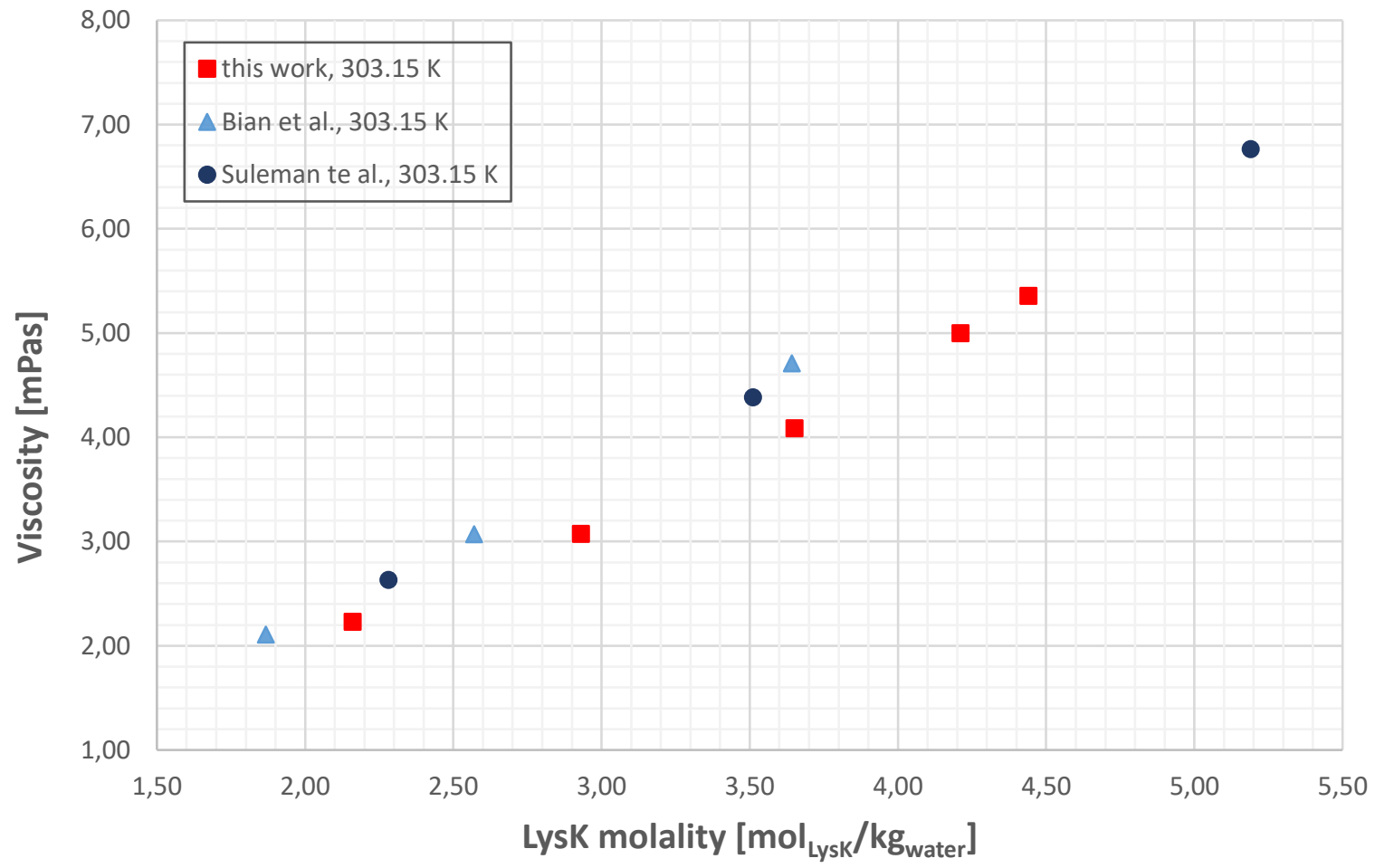

Figure 5: Comparison of experimental data on density at $303.15 \mathrm{~K}$ of LysK solution at various molality concentrations ( $\square$ this work, $\Delta$ Bian et al. ${ }^{18}$, o Suleman et al. ${ }^{20}$.

The experimental data obtained in this work have been used to calibrate the models presented in paragraph 4. These correlations are able to reproduce the behaviour of density and viscosity of LysK solutions as a function of the AAS concentration, temperature and $\mathrm{CO}_{2}$ loading. As expected, both thermophysical 
properties have the same trend: they decrease by increasing the temperature of the system, while they increase with the AAS concentration and the $\mathrm{CO}_{2}$ loading in solution.

For unloaded solutions in particular, the temperature of the system and the solvent composition seems to affect in a similar way the value of density: from two hypothetical absorber and regenerator temperatures (linearly extrapolated) and from least concentrated to most concentrated solution, the density variation is around $0.05 \mathrm{gcm}^{-3}$. Viscosity of unloaded solutions exhibit a more complex behaviour: while for low values of LysK molalities moderate variations of viscosity are registered with temperature changes, for highly concentrated solution viscosity tends to increase significantly, and not linearly, below 310-320 K, with a behavior similar to amine-based solvents ${ }^{33}$.

Density of loaded solutions varies of $40 \mathrm{~kg} / \mathrm{m}^{3}$ between $293 \mathrm{~K}$ and $358 \mathrm{~K}$, regardless of the $\mathrm{CO}_{2}$ content; this last factor causes an increase in the density value of $7 \%$ from the unloaded solution to a $0.98 \mathrm{molCO} / 2 \mathrm{molLysK}$ loaded solution. The $\mathrm{CO}_{2}$ loading in the LysK solvent displayed a strong impact on the viscosity trend: even moderate $\mathrm{CO}_{2}$ levels $(0.33 \mathrm{molCO} / \mathrm{molLysK})$ result in viscosity values 2.5 times higher than the unloaded solution on average, while for high $\mathrm{CO}_{2}$ concentration the average increase is almost 4 times higher. It is worth remarking that as the solution absorbs $\mathrm{CO}_{2}$, its ionic strength increases significantly, leading to strong molecular interactions and this can explain the impeding of transport properties such as viscosity.

The authors would like to point out that during the experimental campaigns neither of the tested solution has formed a solid precipitate, even at the lowest temperature (288 K), highest loading $(0.98)$ and solvent concentration considered (4.44 m).

For what concerns the modelling part of the work, the values of average absolute deviation (AAD) are 0.00054 $\mathrm{gcm}^{-3}$ for density and $0.0148 \mathrm{mPas}$ for viscosity of unloaded solutions. The correlations developed for the $\mathrm{CO}_{2}$ loaded solutions can reproduce the density and the viscosity with an AAD of $0.00148 \mathrm{gcm}^{-3}$ and $0.04 \mathrm{mPas}$, respectively. As can be noticed from Figure 6, Figure 7, Figure 8 and Figure 9, models provide a good fitting of the experimental data, thus demonstrating the reliability of the thermophysical properties correlations adopted in the range of interest. 


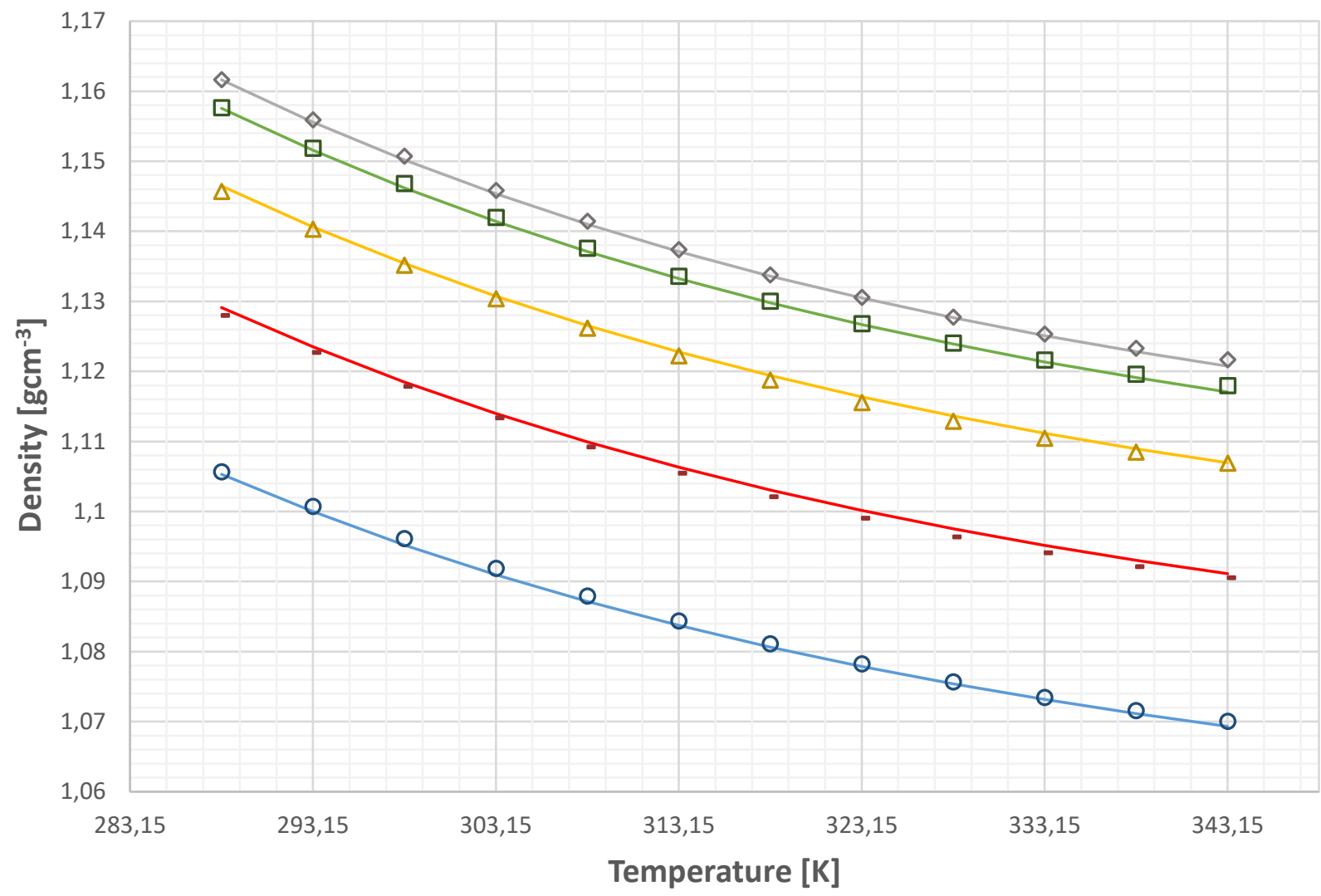

Figure 6: Experimental density (dots) and model predictions (lines) of unloaded LysK solutions at $2.16 \mathrm{~m}(0), 2.93 \mathrm{~m}(-), 3.65 \mathrm{~m}(\Delta)$, $4.21 \mathrm{~m}(\square), 4.44 \mathrm{~m}(\diamond)$ LysK molality from $288.15 \mathrm{~K}$ to $343.15 \mathrm{~K}$.

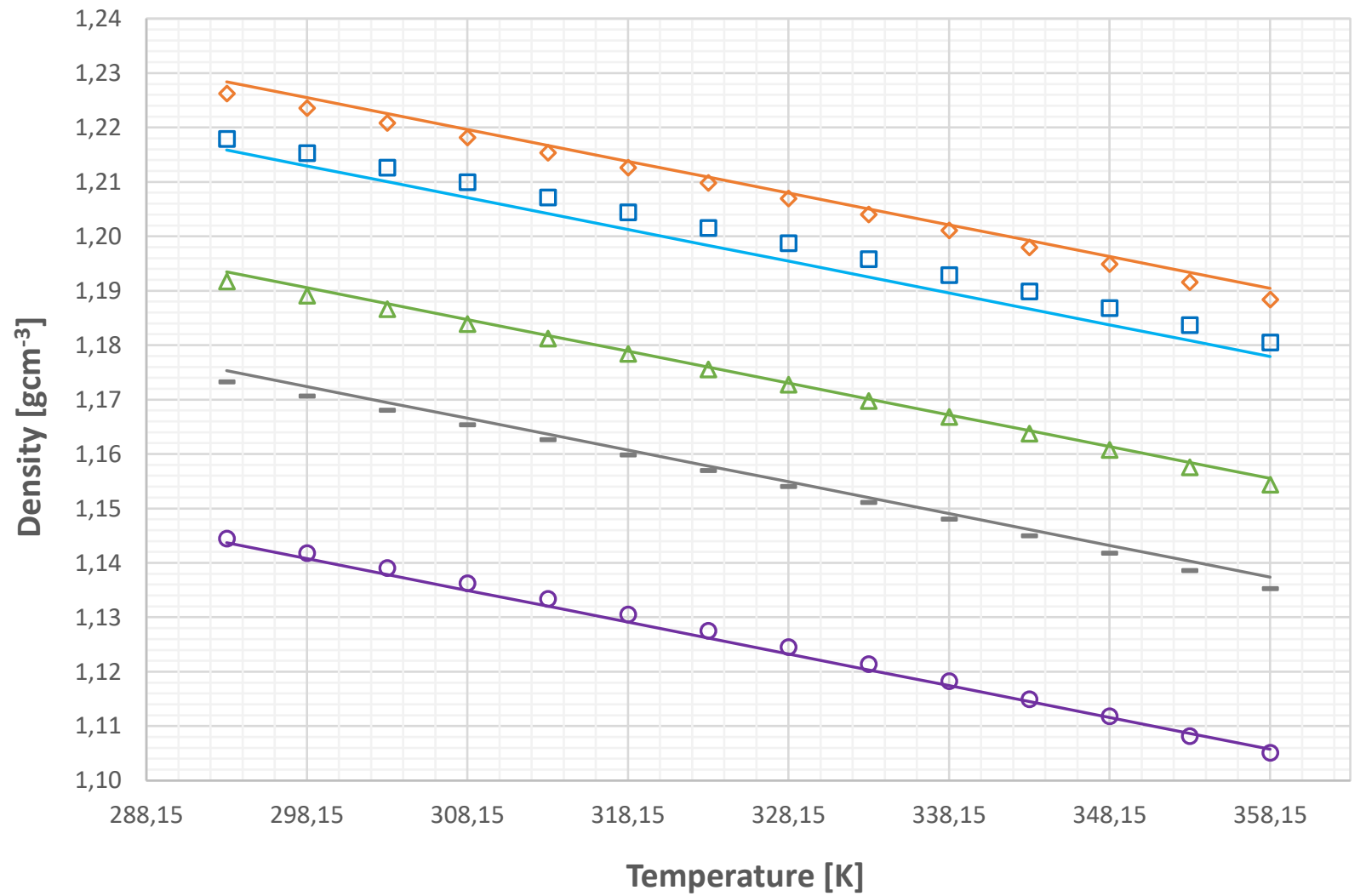

Figure 7: Experimental density (dots) of $\mathrm{CO}_{2}$ loaded LysK solutions at $4.21 \mathrm{~m}$ and model predicitions (lines) from $293.15 \mathrm{~K}$ to $358.15 \mathrm{~K}$. The 4 different $\mathrm{CO}_{2}$ loadings are $0.29(-), 0.49(\Delta), 0.78(\square), 0.98(\diamond) \mathrm{mol} \mathrm{CO}_{2} / \mathrm{mol} \mathrm{LysK}$; it is reported also the density of the unloaded solution at $43.7 \% \mathrm{w} / \mathrm{w}(0)$. 


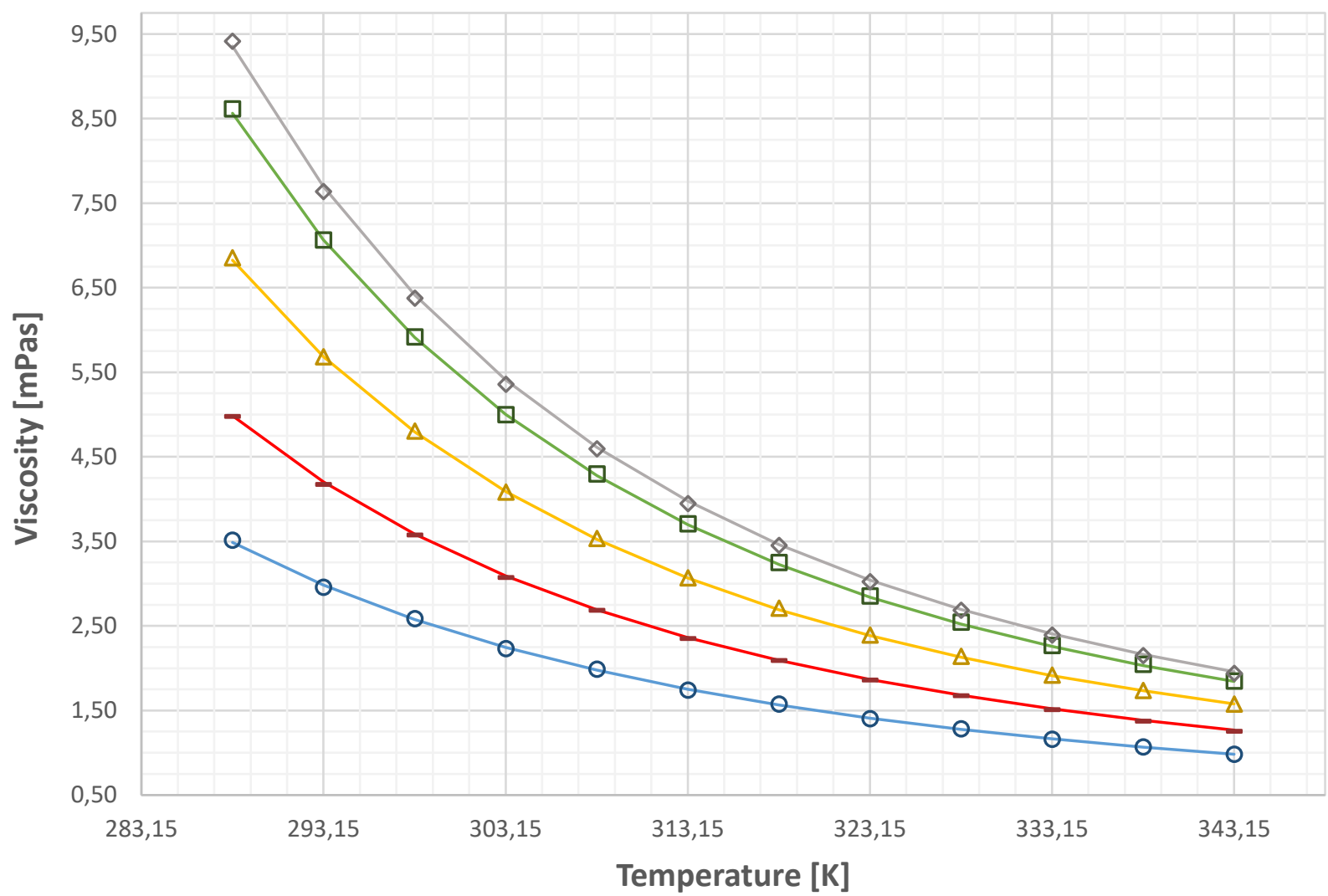

Figure 8: Experimental viscosity (dots) and model predictions (lines) of unloaded LysK solutions at $2.16 \mathrm{~m}(0), 2.93 \mathrm{~m}(-), 3.65 \mathrm{~m}(\Delta)$ ), $4.21 \mathrm{~m}(\square), 4.44 \mathrm{~m}(\diamond)$ LysK molality from $288.15 \mathrm{~K}$ to $343.15 \mathrm{~K}$.

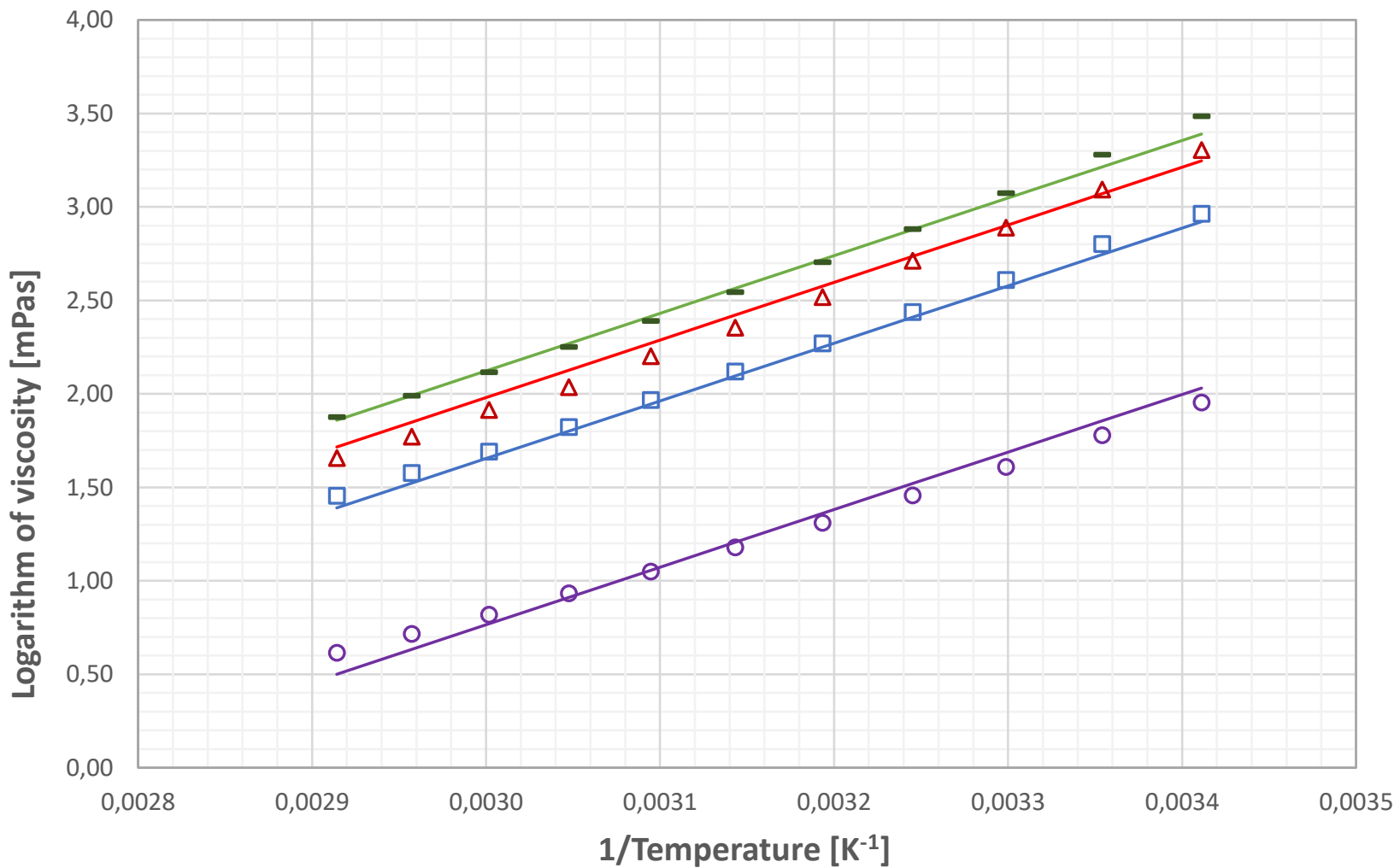

Figure 9: Experimental viscosity (dots) of $\mathrm{CO}_{2}$ loaded Lys $\mathrm{K}$ solutions at $4.21 \mathrm{~m}$ and model predictions (lines) from $293.15 \mathrm{~K}$ to 343.15 $K$. The 3 different $\mathrm{CO}_{2}$ loadings are $0.33(\square), 0.54(\Delta)$ and $0.81(-) \mathrm{mol} \mathrm{CO} / 2 \mathrm{~mol} L y s K$; it is reported also the viscosity of the unloaded solution at $43.7 \% \mathrm{w} / \mathrm{w}(\mathrm{O})$. 
To further extend and verify the applicability of these models for predictive purposes, outside their calibration range, validation against literature data presented in the work of Suleman et al. ${ }^{20}$ is conducted. Experimental data-set reported by Suleman involve density and viscosity measurements of unloaded LysK solutions of $2.28 \mathrm{~m}, 3.51 \mathrm{~m}$ and $5.19 \mathrm{~m}$, temperature range $\mathrm{T}=(303.15$ to 343.15$) \mathrm{K}$. The results are presented in the parity plots below (Figure 10 and Figure 11) where the values calculated by the models are plotted against the literature values. For density, the agreement between the model and literature data is very good, with discrepancies lower than $3 \%$ of the measured value. For viscosity, deviations increase, but the great majority of the points are included within $\pm 10 \%$ relative error range, hence indicating a good applicability of these equations also in the case of LysK concentration values outside the calibration range of the models.

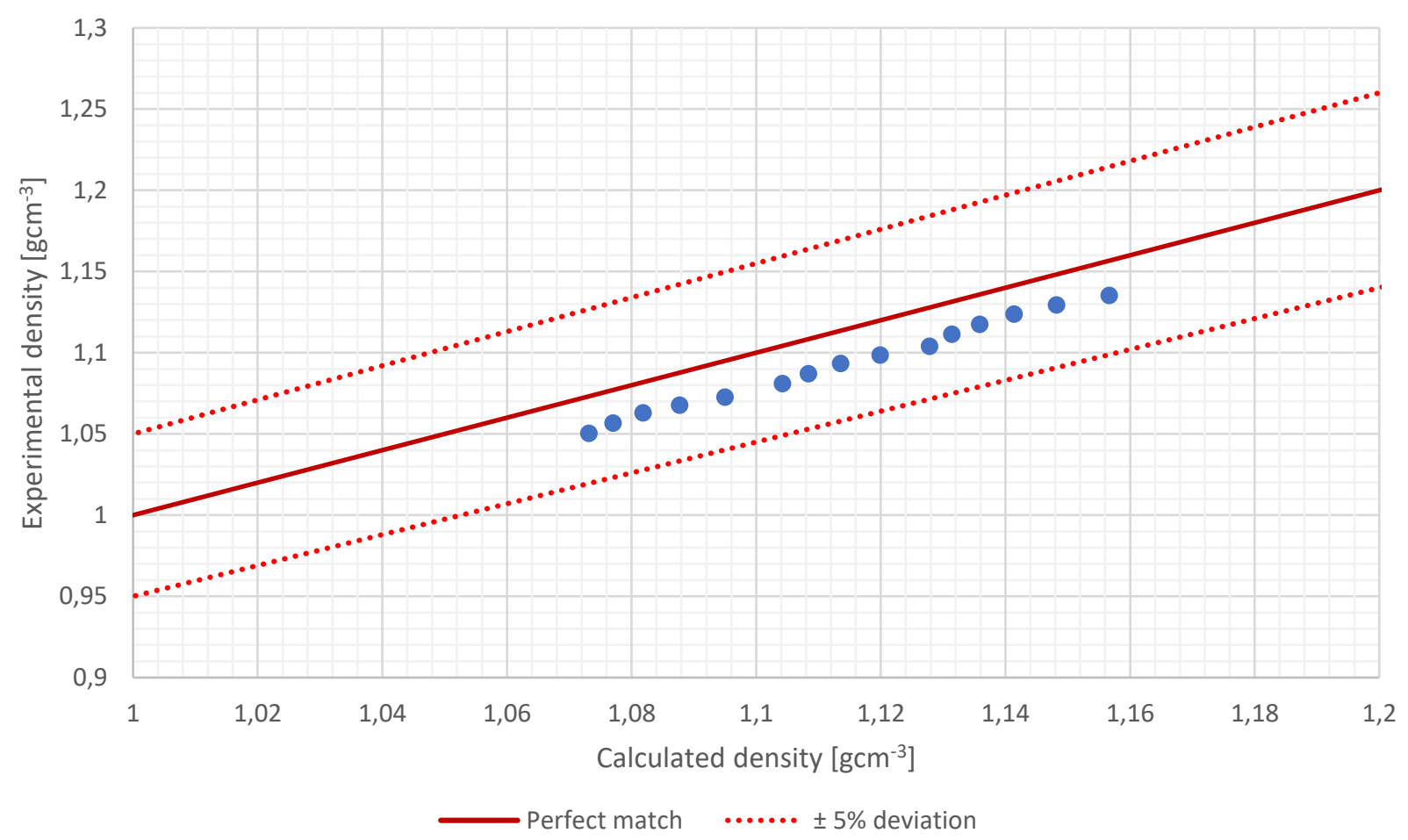

Figure 10: Parity plot of the density values calculated by the model developed and the actual literature values provided in Suleman et al.[24]. The results are plotted against $\pm 10 \%$ of error deviation from the perfect match. 


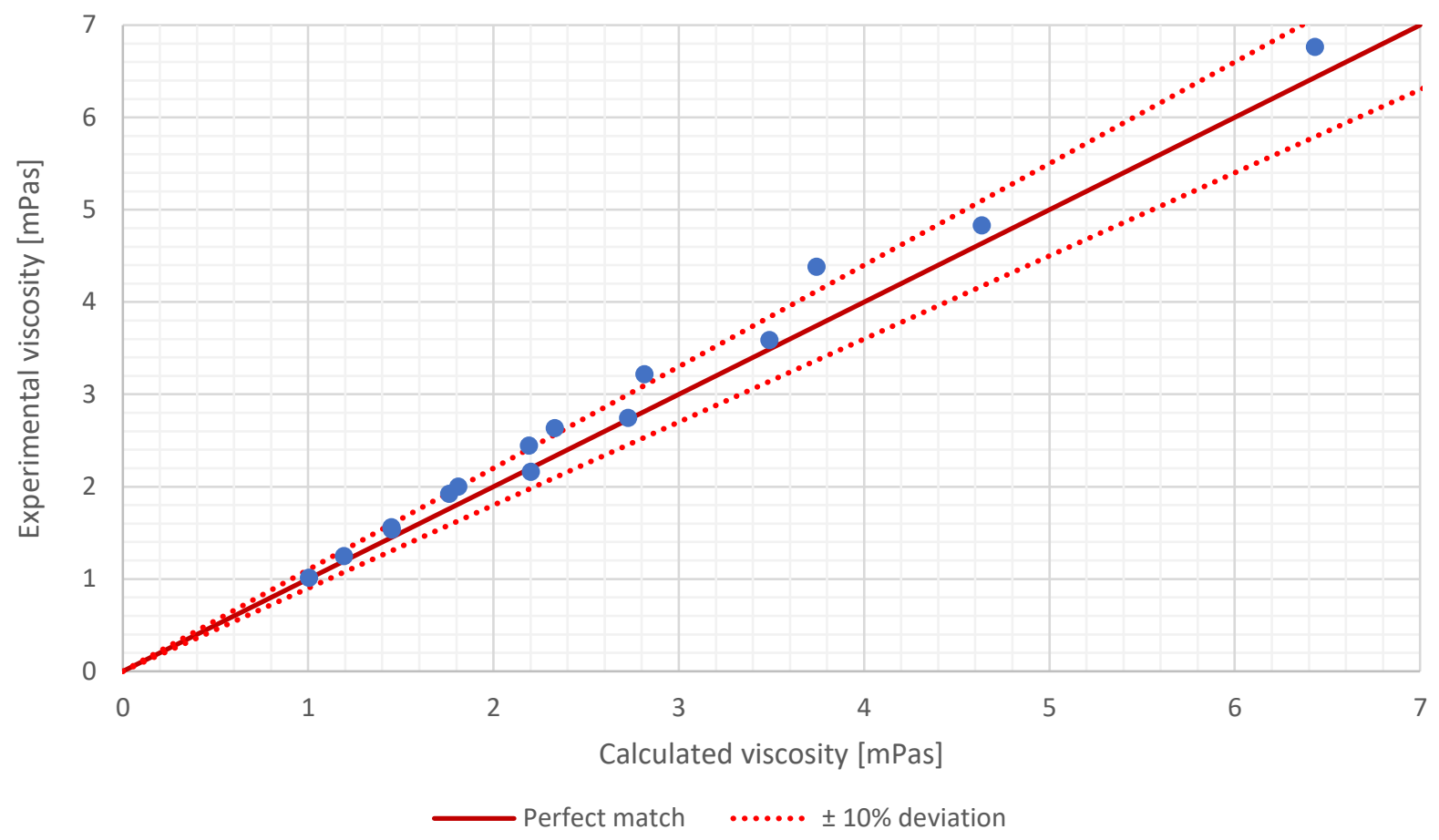

Figure 11: Parity plot of the viscosity values calculated by the model developed and the actual literature values provided in Suleman et al.[24]. The results are plotted against $\pm 10 \%$ of error deviation from the perfect match.

In the context of research and development of new chemical solvents such as LysK aqueous solutions, besides assessing the kinetics and thermodynamics performance of the solvent (VLE data, maximum $\mathrm{CO}_{2}$ loading, kinetics rate, capacity, etc.), a comparison between density and viscosity is recommended in order to establish if the new solvent (e.g. LysK) might be a viable and superior alternative to the benchmark ( $30 \% \mathrm{w} / \mathrm{w}$ MEA). The plots of Figure 12 and Figure 13 show, respectively, the behaviour of density and viscosity with temperature at different $\mathrm{CO}_{2}$ loadings for aqueous $30 \% \mathrm{w} / \mathrm{w}$ (or $7 \mathrm{~m}$ ) MEA ${ }^{34}$, and for $43.7 \% \mathrm{w} / \mathrm{w}$ (or $4.21 \mathrm{~m}$ ) LysK solutions tested in this work. Even for lower molality concentration, due to the larger molecular weight and high ionic strength of even unloaded mixtures, LysK solutions are characterized by higher values of density and viscosity compared to MEA solutions. In the temperature and $\mathrm{CO}_{2}$ loading range investigated in this work, the density of $43.7 \% \mathrm{w} / \mathrm{w}$ LysK is between 7 and $13 \%$ higher compared to the density of MEA under the same conditions.

The effect of $\mathrm{CO}_{2}$ loading on density is more significant for the amine solution, where the percentage increase, when loading raises from 0 to $0.5 \mathrm{molCO}_{2} / \mathrm{molLysK}$, is up to $10 \%$, whereas the same parameter for LysK solvents increases by $4 \%$.

The viscosity of LysK solution is strongly affected by the $\mathrm{CO}_{2}$ content, and this phenomenon is even more significant for LysK compared to MEA: at $0.5 \mathrm{molCO}_{2} / \mathrm{molLysK}$ the maximum viscosity (i.e. the one measured at $293 \mathrm{~K}$ ) is 4 times higher than the one of the unloaded solution, whereas for MEA solutions the corresponding relative increase is close to 1.5 times.

The typical range of MEA dynamic viscosity envisaged within a $\mathrm{CO}_{2}$ absorber $\left(\mathrm{CO}_{2}\right.$ loading up to 0.5 and temperatures between $303 \mathrm{~K}$ and $343 \mathrm{~K}$ ) is between 0.9 and $3.2 \mathrm{mPas}$, while the range measured for Lysk under the same conditions is between 1.9 and $18 \mathrm{mPas}$. As a result, LysK dynamic viscosity under loaded conditions can be up to 6 times larger than the one of MEA.

In a $\mathrm{CO}_{2}$ absorption process, a larger viscosity leads to reduced mass and heat transfer between the gas and liquid phase (e.g correlation by Onda et al. ${ }^{15}$ and Chilton and Colburn ${ }^{35}$ ). Moreover, a higher viscosity leads to larger pressure drops and solvent circulation pumps auxiliary consumption. In any case, since other solvent properties may play a counteracting role compared to the one here described for viscosity (e.g. improved 
kinetics, lower vapor pressure), comprehensive tecno-economic studies are needed to fully evaluate the solvent performance, as well as to address its competitiveness against the benchmark. Moreover, other criteria can lead to the selection of LysK over MEA as a $\mathrm{CO}_{2}$ capture solvent, such as lower toxicity and volatility, thermal degradation properties, etc.

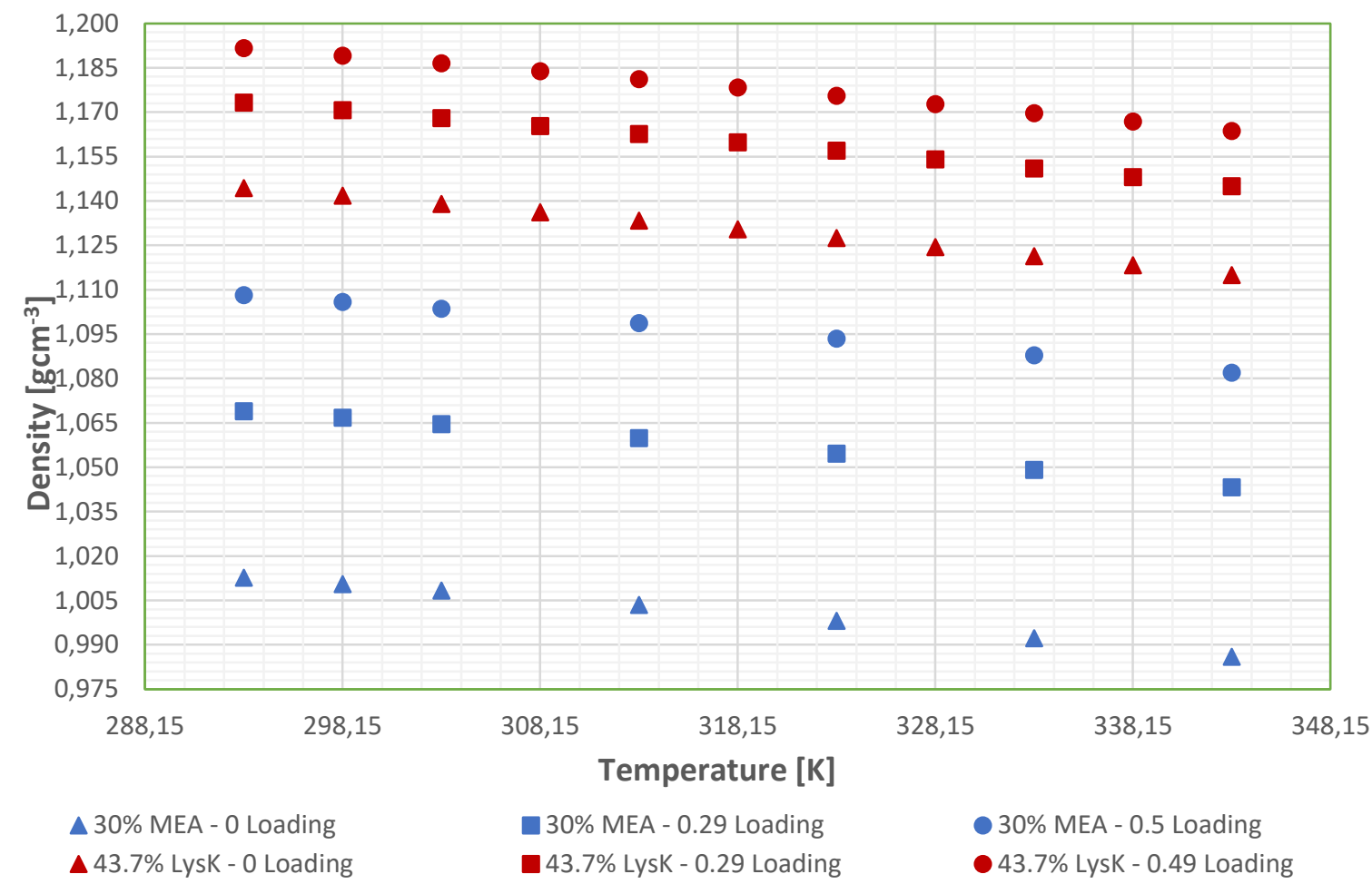

Figure 12: Experimental density of $\mathrm{CO}_{2}$ loaded $7 \mathrm{~m} \mathrm{MEA}^{34}$ (blue) and $4.21 \mathrm{~m} \mathrm{LysK}$ (red) solutions at similar $\mathrm{CO}_{2}$ concentration levels: $\mathrm{O}(\Delta)-0.29(\square)-0.5(\mathrm{O}) \mathrm{molCO}_{2} / \mathrm{molLysK}^{\circ}$ 


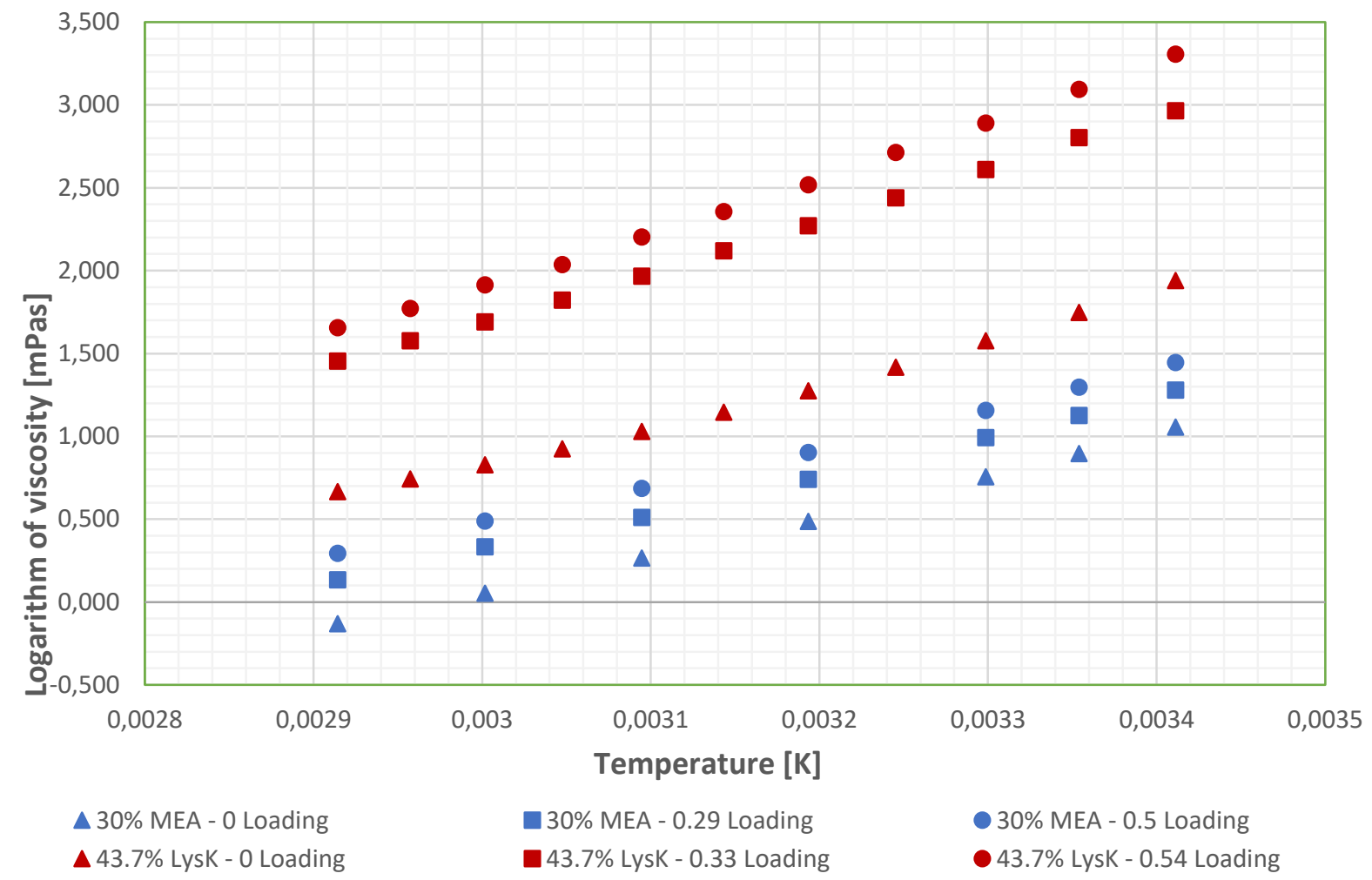

Figure 13: Experimental viscosity of $\mathrm{CO}_{2}$ loaded $7 \mathrm{~m} \mathrm{MEA}^{34}$ (blue) and $4.21 \mathrm{~m} \mathrm{LysK} \mathrm{(red)} \mathrm{solutions} \mathrm{at} \mathrm{similar} \mathrm{CO}_{2}$ concentration levels: $\mathrm{O}(\Delta)-0.29(\square)-0.5(0) \mathrm{molCO}_{2} / \mathrm{molLysK}^{-}$

\section{Conclusions}

This work presents a new set of experimental data and related empirical correlations of densities and viscosities of aqueous LysK solutions, in a concentration range from $2.16 \mathrm{~m}$ to $4.44 \mathrm{~m}$, a temperature range $\mathrm{T}=(288.15$ to 358.15$) \mathrm{K}$ and $\mathrm{CO}_{2}$ loadings from $0.3 \mathrm{molCO} / \mathrm{molLysK}$ to $0.98 \mathrm{molCO} / \mathrm{molLysK}$. The main contributions to the existing literature are the experimental values, and newly formulated models, for density and viscosity of $\mathrm{CO}_{2}$ loaded LysK solutions at a concentration level of $4.21 \mathrm{~m}$. In fact, such high LysK concentration level has never been investigated for carbonated solutions, in view of $\mathrm{CO}_{2}$ capture applications. The uncertainty achieved on the experimental points is below $10 \%$ for most of the data obtained and in accordance with the values reported in literature for similar works ${ }^{16,18,19}$.

The empirical models developed in this work reproduce the values of density and viscosity at different Lysk concentration levels and temperatures for what concerns the unloaded solutions, and at different temperatures and $\mathrm{CO}_{2}$ loadings for the $\mathrm{CO}_{2}$ loaded solutions. These correlations fit the new experimental data presented in this study with an AAD equal to $0.00054 \mathrm{gcm}^{-3}$ and $0.00148 \mathrm{gcm}^{-3}$ for density of unloaded and loaded solutions respectively, while for the viscosity the reported AAD values are $0.0148 \mathrm{mPas}$ and 0.04 mPas respectively for the unloaded solutions and for the $\mathrm{CO}_{2}$ loaded ones. Furthermore, the proposed models have been verified against experimental data available in literature ${ }^{20}$, reporting the density and viscosity of LysK aqueous solutions at $2.28 \mathrm{~m}, 3.51 \mathrm{~m}, 5.19 \mathrm{~m}$ LysK molality concentrations and temperature range $\mathrm{T}=(303.15$ to 343.15$) \mathrm{K}$. 


\section{Supporting Information}

The Supporting Information file contains the results of the quartz viscometer calibration (figures and tables). It also presents the procedures applied for the calculation of the experimental standard and combined uncertainty and the statistical analysis on modelling results.

\section{Acknowledgment}

The activities have been carried out with the support of the Erasmus+ programme of the European Union. The authors would also like to thank the Mines ParisTech University for the support and the Centre of Thermodynamics of Processes for the laboratory facility.

\section{References}

1. Sanchez Fernandez, E.; Goetheer, E.L.V.; Manzolini, G.; Macchi, E.; Rezvani, S.; Vlugt, T.J.H.; Thermodynamic assessment of amine based $\mathrm{CO} 2$ capture technologies in power plants based on European Benchmarking Task Force methodology. Fuel. Elsevier Ltd; 2014;129:318-329.

2. Rochelle, G.T.; Conventional amine scrubbing for $\mathrm{CO} 2$ capture. Absorption-Based Post-Combustion Capture of Carbon Dioxide. 2016 p. 35-67.

3. MacDowell, N.; Florin, N.; Buchard, A.; Hallett, J.; Galindo, A.; Jackson, G.; Adjiman, C.; Williams, C.; Shahb, N.; Fennel, P.; An overview of CO2 capture technologies. Energy Environ Sci. 2010;3:16451669.

4. Lee, S.; Choi, S.I.; Maken, S.; Song, H.J.; Shin, H.C.; Park, J.W.; Jang, K.R.; Kim, J.H.; Physical properties of aqueous sodium glycinate solution as an absorbent for carbon dioxide removal. J Chem Eng Data. 2005;50:1773-1776.

5. Hwang, G.S.; Stowe, H.M.; Paek, E.; Manogaran, D.; Reaction mechanisms of aqueous monoethanolamine with carbon dioxide: A combined quantum chemical and molecular dynamics study. Phys Chem Chem Phys. Royal Society of Chemistry; 2015;17:831-839.

6. Zhao, Y.; Bian, Y.; Li, H.; Guo, H.; Shen, S.; Han, J.; Guo, D.; A Comparative Study of Aqueous Potassium Lysinate and Aqueous Monoethanolamine for Postcombustion CO 2 Capture. Energy and Fuels. 2017;31:14033-14044.

7. Bian, Y.; Shen, S.; Modeling of $\mathrm{CO} 2$ Solubility in Aqueous Potassium Lysinate Solutions at PostCombustion CO2 Capture Conditions. IOP Conf Ser Earth Environ Sci. 2017;68.

8. Shen, S.; Zhao, Y.; Bian, Y.; Wang, Y.; Guo, H.; Li, H.; CO2 absorption using aqueous potassium lysinate solutions: Vapor - liquid equilibrium data and modelling. J Chem Thermodyn. Elsevier Ltd; 2017;115:209-220.

9. Shen, S.; Yang, Y.N.; Bian, Y.; Zhao, Y.; Kinetics of CO2 Absorption into Aqueous Basic Amino Acid Salt: Potassium Salt of Lysine Solution. Environ Sci Technol. 2016;50:2054-2063.

10. Conversano, A.; Porcu, A.; Mureddu, M.; Pettinau, A.; Gatti, M.; Bench-Scale Absorption Testing of Aqueous Potassium Lysinate as a New Solvent for CO 2 Capture in Natural Gas-Fired Power Plants. Int J Greenh Gas Control. Elsevier Ltd; 2021;106:103268.

11. Zhao, Y.; Shen, S.; Bian, Y.; Yang, Y.; Ghosh, U.; CO2 solubility in aqueous potassium lysinate solutions at absorber conditions. J Chem Thermodyn. Elsevier Ltd; 2017;111:100-105.

12. Green, D.W.; Perry, R.H.; Perry's Chemical Engineers' Handbook. 8th ed. The McGraw-Hill companies; 2008. 
13. Mota-Martinez, M.T.; Hallett, J.P.; Mac Dowell, N.; Solvent selection and design for CO2 capturehow we might have been missing the point. Sustain Energy Fuels. Royal Society of Chemistry; 2017;1:2078-2090.

14. Xu, Z.; Singh, R.K.; Bao, J.; Wang, C.; Direct Effect of Solvent Viscosity on the Physical Mass Transfer for Wavy Film Flow in a Packed Column. Ind Eng Chem Res. 2019;58:17524-17539.

15. Onda, K.; Takeuchi, H.; Okumoto, Y.: Mass transfer coefficients betweengas and liquid phases in packed columns. J Chem Eng Japan. 1968;1:56-61.

16. Shen, S.; Yang, Y.; Wang, Y.; Ren, S.; Han, J.; Chen, A.; CO2 absorption into aqueous potassium salts of lysine and proline: Density, viscosity and solubility of CO2. Fluid Phase Equilib. Elsevier B.V.; 2015;399:40-49.

17. Mazinani, S.; Ramazani, R.; Samsami, A.; Jahanmiri, A.; Van der Bruggen, B.; Darvishmanesh, S.; Equilibrium solubility, density, viscosity and corrosion rate of carbon dioxide in potassium lysinate solution. Fluid Phase Equilib. Elsevier B.V.; 2015;396:28-34.

18. Bian, Y.; Shen, S.; Zhao, Y.; Yang, Y.N.; Physicochemical properties of aqueous potassium salts of basic amino acids as absorbents for CO2 capture. J Chem Eng Data. 2016;61:2391-2398.

19. Ramezani, R.; Mazinani, S.; Di Felice, R.; A comprehensive kinetic and thermodynamic study of CO2 absorption in blends of monoethanolamine and potassium lysinate: Experimental and modeling. Chem Eng Sci. Elsevier Ltd; 2019;206:187-202.

20. Suleman, H.; Fosbøl, P.L.; Physicochemical Data of Carbonic-Anhydrase-Blended Aqueous Potassium Lysinate Solutions as New Absorbents. J Chem Eng Data. 2020;65:2383-2391.

21. Span, R.; Wagner, W.; A new equation of state for carbon dioxide covering the fluid region from the triple-point temperature to $1100 \mathrm{~K}$ at pressures up to $800 \mathrm{MPa}$. J Phys Chem Ref Data. 1996;25:1509-1596.

22. Lemmon, E.W.; Bell, I.H.; Huber, M.L.; McLinden, M.O.; NIST Standard Reference Database 23: Reference Fluid Thermodynamic and Transport Properties-REFPROP, Version 10.0. Natl Inst Stand Technol Stand Ref Data Program, Gaithersbg. 2018

23. Lampreia, I.M.S.; Nieto De Castro, C.A.; A new and reliable calibration method for vibrating tube densimeters over wide ranges of temperature and pressure. J Chem Thermodyn. Elsevier Ltd; 2011;43:537-545.

24. Anton Paar GmbH. Reference Manual DSA 5000 M. 2011.

25. Anton Paar GmbH. Reference Manual Lovis $2000 \mathrm{M} / \mathrm{ME}$.

26. Flucon fluid control GmbH - QVis 01/L User manual.

27. Laesecke, A.; Meier, K.; Hafer, R.F.; Wide-ranging absolute viscosity measurements of sub- and supercritical 1,1,1-trifluoroethane (R143a). J Mol Liq. Elsevier B.V.; 2018;251:128-141.

28. International Organization for Standardization Geneva ISBN. Evaluation of measurement data Guide to the expression of uncertainty in measurement. 2008.

29. Garcia, A.A.R.; Leron, R.B.; Soriano, A.N.; Li, M.H.; Thermophysical property characterization of aqueous amino acid salt solutions containing $\alpha$-aminobutyric acid. J Chem Thermodyn. Elsevier Ltd; 2015;81:136-142.

30. Tirona, L.A.; Leron, R.B.; Soriano, A.N.; Li, M.H.; Densities, viscosities, refractive indices, and electrical conductivities of aqueous alkali salts of $\alpha$-alanine. J Chem Thermodyn. Elsevier Ltd; 2014;77:116-122. 
31. Garg, S.; Shariff, A.M.; Shaikh, M.S.; Lal, B.; Aftab, A.; Faiqa, N.; Selected physical properties of aqueous potassium salt of L-phenylalanine as a solvent for $\mathrm{CO} 2$ capture. Chem Eng Res Des. Institution of Chemical Engineers; 2016;113:169-181.

32. Navarro, S.S.; Leron, R.B.; Soriano, A.N; Li, M.H.; Thermophysical property characterization of aqueous amino acid salt solution containing serine. J Chem Thermodyn. Elsevier Ltd; 2014;78:23-31.

33. Arachchige, U.S.P.R.; Aryal, N.; Eimer, D.A.; Melaaen, M.C.; Viscosities of Pure and Aqueous Solutions of Monoethanolamine (MEA), Diethanolamine (DEA) and N-Methyldiethanolamine (MDEA). Annu Trans Nord Rheol Soc. 2013;21:299-306.

34. Hartono, A.; Mba, E.O.; Svendsen, H.F.; Physical Properties of Partially CO 2 Loaded Aqueous. 2014.

35. Taylor, R.; Krishna, R.; Multicomponent Mass Transfer. 1993. 


\section{For Table of Contents Only}

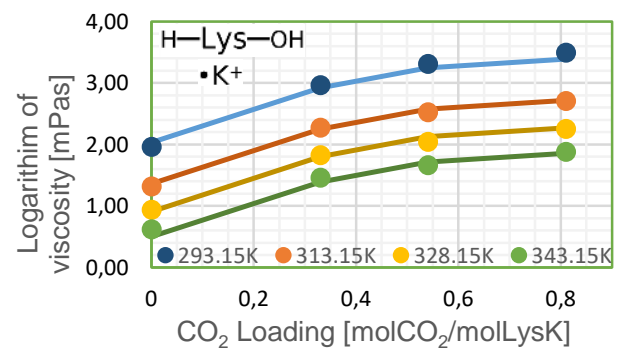

